\title{
Brookhaven Synchrotron WAXS and SAXS Studies of Kel-F $\mathbf{8 0 0}$
}

\author{
B. Cook
}

December 3, 1999

U.S. Department of Energy

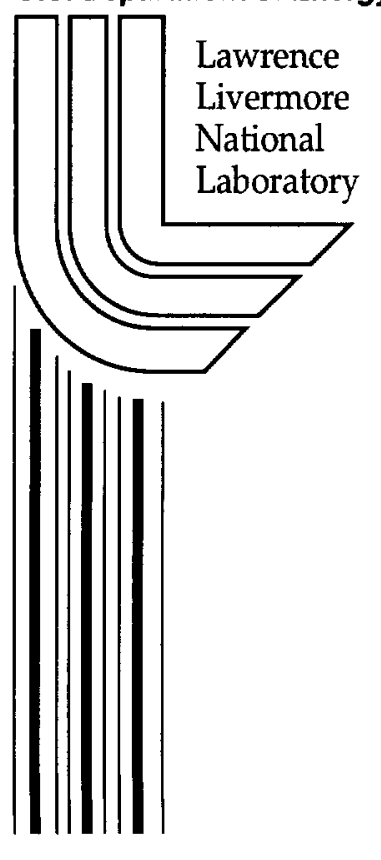




\section{DISCLAIMER}

This document was prepared as an account of work sponsored by an agency of the United States Government. Neither the United States Government nor the University of California nor any of their employees, makes any warranty, express or implied, or assumes any legal liability or responsibility for the accuracy, completeness, or usefulness of any information, apparatus, product, or process disclosed, or represents that its use would not infringe privately owned rights. Reference herein to any specific commercial product, process, or service by trade name, trademark, manufacturer, or otherwise, does not necessarily constitute or imply its endorsement, recommendation, or favoring by the United States Government or the University of California. The views and opinions of authors expressed herein do not necessarily state or reflect those of the United States Government or the University of California, and shall not be used for advertising or product endorsement purposes.

This work was performed under the auspices of the U. S. Department of Energy by the University of California, Lawrence Livermore National Laboratory under Contract No. W-7405-Eng-48.

This report has been reproduced directly from the best available copy.

Available electronically at http://www.doe.gov/bridge

Available for a processing fee to U.S. Department of Energy

and its contractors in paper from

U.S. Department of Energy

Office of Scientific and Technical Information

P.O. Box 62

Oak Ridge, TN 37831-0062

Telephone: (865) 576-8401

Facsimile: (865) 576-5728

E-mail: reports@adonis.osti.gov

Available for the sale to the public from

U.S. Department of Commerce

National Technical Information Service

5285 Port Royal Road

Springfield, VA 22161

Telephone: (800) 553-6847

Facsimile: (703) 605-6900

E-mail: orders@ntis.fedworld.gov

Online ordering: http://www.ntis.gov/ordering.htm

OR

Lawrence Livermore National Laboratory

Technical Information Department's Digital Library

http://www.llnl.gov/tid/Library.html 


\title{
Brookhaven Synchrotron WAXS and SAXS studies of Kel-F 800
}

\author{
Bob Cook \\ Lawrence Livermore National Laboratory
}

\section{Introduction and overview of key results.}

On August 11 - 13, 1999, Cheng Saw and I collected WAXS and SAXS data on KelF 800 and poly(chlorotrifluoroethane) (pCTFE) polymer samples using the Advanced Polymer Beamline at the National Synchrotron Light Source at Brookhaven National Laboratory. The purpose of these experiments was to attempt to gain insight into the structure of the polymer in both amorphous and crystalline states. Developing this understanding is important if we are to 1) adequately understand the changing per cent crystallinity aging signature seen in LX-17 and 2) to be able to appropriately prepare "aged" samples of LX-17.

One of the key questions we hoped to answer concerns the origin of the fairly sharp WAXS peak seen at a correlation length of about $5.6 \AA$. It is known that the crystalline peaks of PCTFE and Kel-F 800 occur at this position, but they are superimposed on a much stronger amorphous peak at exactly the same position. I had previously suggested that the relatively sharp amorphous peak was due to a possible helical structure of the chain backbone. ${ }^{1}$ As will be described below, experiments to test this idea conclusively showed it not to be correct. In addition the preliminary results from molecular dynamics modeling studies of Kel-F 800 now underway by Rick Gee ${ }^{2}$ show that the sharp $5.6 \AA$ peak is present in condensed, unstructured (non-helical) chains. These studies should be able to provide detailed information about its structural origins.

The data collected can be divided into three sets. Appendix A contains a detailed listing of all the 68 data sets collected identifying the sample and its history. The first set focused on Kel-F 800 and pCTFE samples with different thermal aging histories and thus different degrees of crystallinity. Although there are perhaps some subtle differences it is fair to say that in the WAXS and SAXS they all look about the same. There is certainly no indication that WAXS measurements are going to be useful in providing an alternative method to DSC for determining degree of crystallinity for Kel$\mathrm{F} 800$. The second set of experiments looked at the temperature dependence of the SAXS and WAXS of initially amorphous Kel-F 800 samples. There are two results here. First the $5.6 \AA$ peak broadens somewhat and shifts as the T is increased but does not disappear as it might if it was due to some quasi-ordered structure. It appears to be a fluid like scattering peak that broadens as one might expect the radial distribution peaks

\footnotetext{
1 Bob Cook, "Some Thoughts on Kel-F 800 Crystallization, memo dated February 16, 1999; Bob Cook, "Experimental Plans for August 11-13 X-Ray Scattering Experiments at Brookhaven National Lab," memo dated June 25, 1999.

${ }^{2}$ Rick Gee, private communication.
} 
degree of crystallinity for Kel-F 800. The second set of experiments looked at the temperature dependence of the SAXS and WAXS of initially amorphous Kel-F 800 samples. There are two results here. First the $5.6 \AA$ peak broadens somewhat and shifts as the $T$ is increased but does not disappear as it might if it was due to some quasi-ordered structure. It appears to be a fluid like scattering peak that broadens as one might expect the radial distribution peaks of a fluid to broaden as the $T$ is increased. Second, from the shift of the maximum as a function of temperature one can determine a linear coefficient of thermal expansion (LCTE) of $5.1 \times 10-4{ }^{\circ} \mathrm{C}^{-1}$, consistent with earlier measurements of Cady and Caley ${ }^{3}$ but clearly more accurate. The third set of data was taken on samples that were uniaxially drawn, either in real time or previously at LLNL. In the case of the latter they were both drawn and aged at elevated T. For the drawn and aged samples data was collected with the 1-D detector both perpendicular and parallel to the draw direction. The results here clearly indicate that the $5.6 \AA$ peak comes from correlations between chains rather than along the chain backbone. The real time draw experiments appear to show that the interchain order that gives rise to the $5.6 \AA$ peak increases as a function of the degree of draw the sample experiences, however the data can also be explained by the thinning the sample experiences during draw.

Cheng Saw has independently prepared a summary report ${ }^{4}$ on the results of these studies which covers some of the information contained in this report. His description of the experimental facilities will not be repeated here except to emphasize that WAXS and SAXS data are collected simultaneously on two linear 1$D$ detectors. Where appropriate I will comment on some of his observations. Our different backgrounds and approaches sometimes lead to different observations and conclusions, and this I believe is a positive situation given the complexity of the problems at hand.

In what follows I will first detail some aspects of the data handling common to all experiments and then individually discuss the results from the three sets of experiments briefly described above.

\section{Data Handling.}

The initial data is collected as counts per detector channel location the 1-D WAXS and SAXS detectors. For each set of runs with the same sample positioning (K1-33, K34-52, K53-68) the channel positions were calibrated on each detector against standards. This allowed us to convert channel position to $2 \theta$, where $\theta$ is the scattering angle, for the WAXS; and to wave vector $q$ for the SAXS data.

\footnotetext{
${ }^{3}$ W. E. Cady and L. E. Caley, Properties of Kel-F 800 Polymer, LLNL UCRL-52301 (1977), as reported in Polymeric Materials, p 235, compiled by B. Dobratz, LLNL M-088, June 30, 1978.

${ }^{4}$ Cheng Saw, "Structural Examination of Kel-F 800 Polymer by Synchrotron Radiation," internal memo \# CKS/99/11, September 8, 1999.
} 
The wavelength, $\lambda$, of the synchrotron source was $1.307 \AA$. The Bragg equation

$$
n \lambda=2 d_{W} \sin \theta
$$

with $n=1$ was used to determine the scattering spacing, $d_{W}$, from the WAXS data. For the SAXS data, which is presented in terms of intensity as a function of the wave vector $q$, the scattering spacing $d_{S}$ is given by

$$
d_{S}=2 \pi / q
$$

The observed WAXS peak width is due to a combination of the spatial extent of the crystallites (if they exist) as well as the degree of local periodic order. Separating these effects is difficult at best, but qualitative comparisons between samples may be useful. For this purpose we will use the simple Scherrer equation ${ }^{5}$

$$
L=\frac{K \lambda}{\beta \cos \theta}
$$

where $L$ is the Scherrer correlation length, $K$ is a constant approximately equal to unity, $\beta$ is the peak width at half height in radians on the $2 \theta$ scale at scattering angle $\theta$. The equation is really valid only for a powder of relatively perfect crystalline particles, and in this case $L$ is a measure of the crystallite size. The analogy is often extended to polymers and $L$ is interpreted as the size of individual crystalline regions. However this is not correct, especially for the very imperfect crystalline samples (and non-crystalline samples) we are considering here. Instead we should simply consider it as an integrated length scale measure of order, where larger values imply greater order. This could mean longer range order or simply better short range order such as that which would be manifest in sharper peaks in a fluid like radial distribution function.

Determining $\beta$ is in fact difficult since baselines are in general not well defined. It is usually the case that the left (low angle) side of the peak is at a significantly higher intensity than the right. This is largely due to air scattering which is discussed below, but for which I have not tried to correct for these qualitative comparisons. One could try to define a slanted baseline, but instead I have defined in most cases the baseline intensity as the minimum intensity reached on the left side of the peak. This will lead to a peak width at half height that is in general smaller than would be obtained if I had used a slanted baseline or tried to deconvolve the peak from the background. However since our purpose will in

${ }^{5}$ H. P. Klug and L. E. Alexander, X-Ray Diffraction Procedures, 2nd Ed, Wiley-Interscience, New York, 1974, p. 656. 
general be for qualitative comparison rather than a quantitative measure of crystallite size, this definition will maintain appropriate consistency.

Primarily because there was variability in sample thickness from sample to sample, variation in the amount of transmission and thus detector counts in general prevents a simple direct comparison of different runs. In order to normalize the data for comparison, I have generally scaled each data set by dividing the counts at each channel by the total number of WAXS or SAXS counts, and then multiplied the result by a constant for each set of scans to be compared to define a roughly 0 to 100 intensity scale. In WAXS plots I have also generally vertically displaced individual traces by adding a constant, in SAXS plots with log scale ordinates the displacement is achieved by multiplying by a power of 2 .

Two other corrections to the WAXS intensity as a function of scattering angle are also called for but have not been applied in this largely qualitative examination which is focused almost entirely on a single peak, and thus a fairly narrow scattering angle range. The first (and smaller) correction is due to the use of a linear detector. As shown in Figure 1, the path length from the sample to the detector increases as the scattering angle increases. This means that the intensity at the detector drops off with increasing value of $2 \theta$. Specifically, for an angular increment $d(2 \theta)$, the detector exposure in the $y$ direction, $d y$, is proportional to $d(2 \theta) /[\cos 2 \theta]^{2}$. To correct for this "spreading" of the scattered beam one needs to divide all intensities by $[\cos 2 \theta]^{2}$, which has the net effect of slightly increasing the intensities at larger scattering angle over what is presented in this report. Another effect related to the use of a linear detector is that scattered $x$-rays entering the detector have a different path length in the detector due to their non-normal entrance, those at oblique angles travel further. The effect of this condition on detector response is unknown to me, and in any case is not an issue that will effect our discussions below.

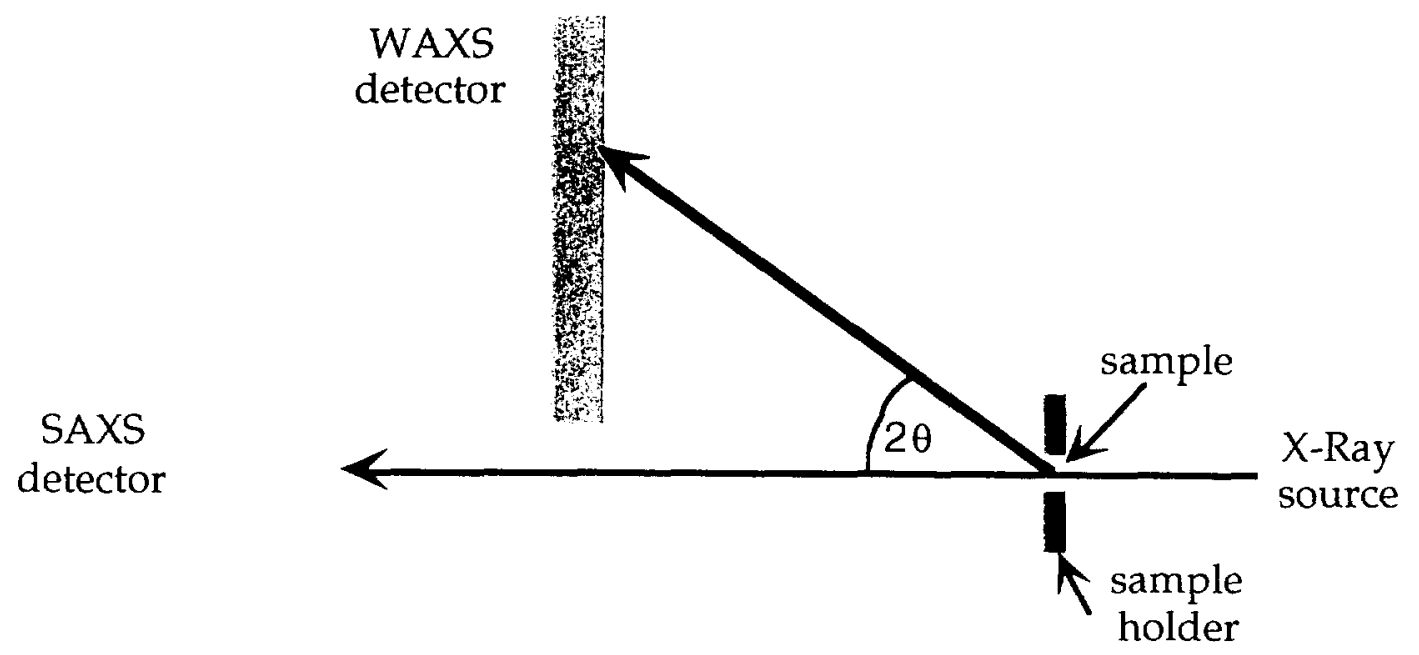

Figure 1. Schematic of experimental set up showing linear WAXS detector. 
The last major correction that should be applied to the data is correction for scattering due to the air after the beam passes through the sample. This scattering can be (and was) measured by making measurements without a sample. What one sees is scattering intensity that drops off rapidly with increasing value of $2 \theta$. In principle this intensity can be subtracted off the observed scattering from a sample, however it must be appropriately scaled and this is somewhat difficult to do consistently. As I will demonstrate below, the correction has a significant effect if one wants to compare intensities in a single scattering experiment at different scattering angle, but has little effect on comparison of scattering at a single scattering angle from different samples.

To illustrate these points we will look at the results from the first 5 sets of data taken (K01 - K05, see appendix A). K01 and K02 were from the same shaved sliver of Kel-F 800, but with different data collection times, K05 was a different sliver from the same piece, and $\mathrm{K} 03$ is data from the full 1-mm thick piece that the slivers were taken from. K04 was collection without sample (a blank). The collection time for sample K01 was $60 \mathrm{~s}$, for the others $120 \mathrm{~s}$. The raw data is shown in Figure 2a. Note that the total number of counts (area under a trace) is highest for the blank since there is no sample attenuation, and lowest for the $1 \mathrm{~mm}$ thick sample. The blank data falls off with increasing scattering angle, and the small scale, high frequency noise is some measure of the counting statistics. There does appear to be a little broad structure in the blank trace that may be due to the thin Kapton windows on the detector. The shaving A, $60 \mathrm{~s}$ trace is very close to one half the intensity of the $120 \mathrm{~s}$ trace, and it would appear that shaving $\mathrm{B}$ was perhaps a little thinner than shaving $\mathrm{A}$. In Figure $2 \mathrm{~b}$ each trace has been normalized to the same number of total counts as described above in order to facilitate comparison between different sets of data. Note that this normalization brings the $60 \mathrm{~s}$ and $120 \mathrm{~s}$ shaving $\mathrm{A}$ data together, as well as magnifying the broad incoherent scattering at high angle in the thick sample. It is in this fashion that most of the data in this report is presented. The issue of how to subtract off the air scattering shown in the blank trace is problematic. The approach suggested by Cheng Saw is shown here. Basically we assume that the scattering we see from polymer samples at low scattering angle is due entirely to air scattering, and that in its absence the scattering curves would decrease to zero at low angle. If this is true then we can pick an angle, in the example here $2 \theta=9^{\circ}$, where the sample scattering ought to be zero, thus it follows that any intensity we see here must be due to air scattering. This allows us to subtract off the blank (air scattering), appropriately scaled so the intensity of the sample is zero at the desired angle, and the sample's corrected intensity, $I_{s}^{c o r}(2 \theta)$, is given as

$$
I_{S}^{c o r}(2 \theta)=I_{S}(2 \theta)-I_{b}(2 \theta) \cdot \frac{I_{S}\left(9^{\circ}\right)}{I_{b}\left(9^{\circ}\right)}
$$

where the intensities on the right side are for the raw sample (s) and blank (b) data as shown in Figure 2a. The resulting $I_{s}^{c o r}(2 \theta)$ data can then be normalized for the 


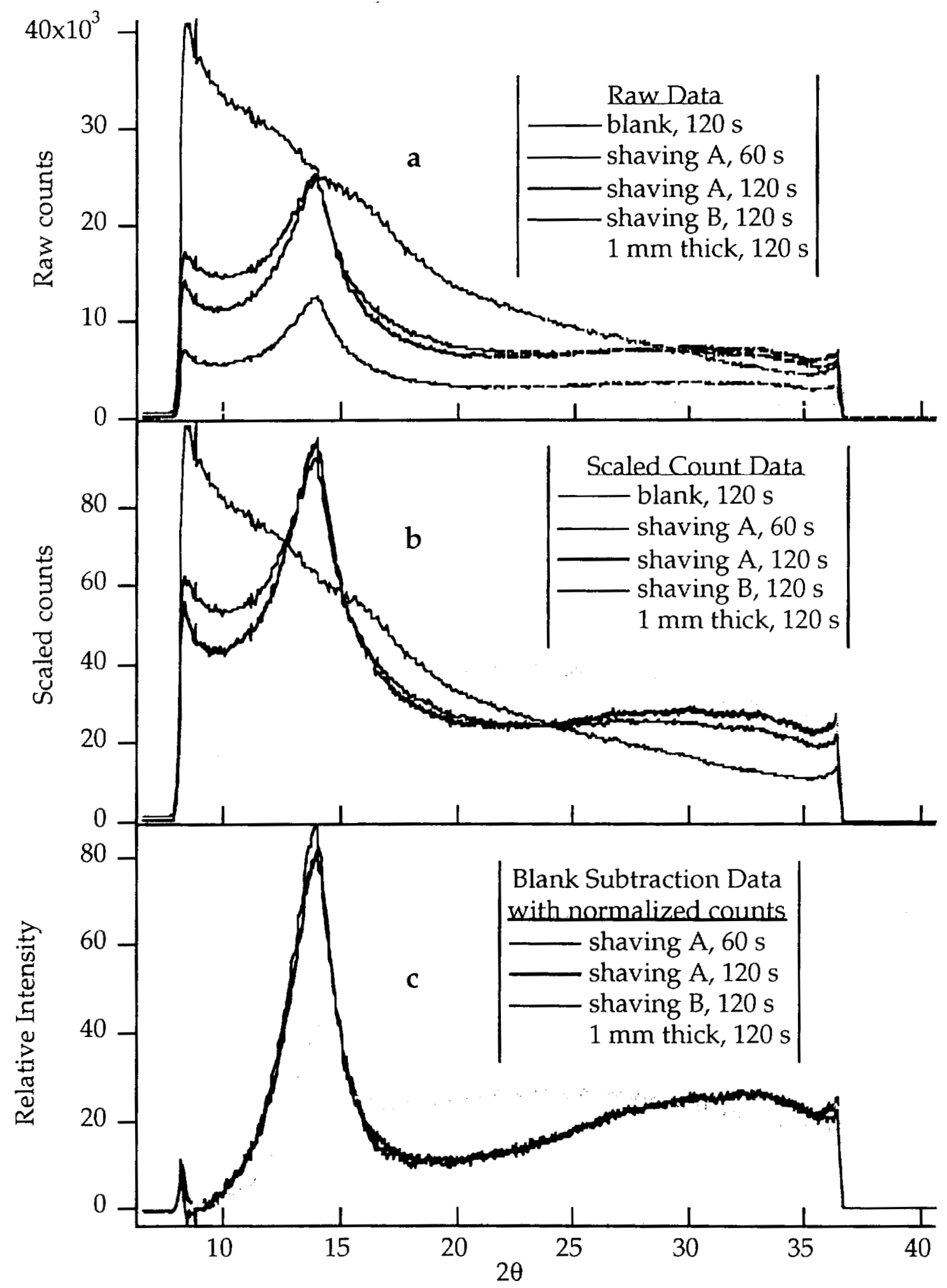

Figure 2. In the top plot (a) the raw data for samples of the same material and a blank are shown. In (b) the data has been normalized so that each trace represents the same number of counts. In (c) the blank has been subtracted off the sample data as described in the text, and the resulting data normalized. 
total number of remaining counts as was done in Figure $2 b$, the result is shown in Figure 2c. The main effect of the blank subtraction is to effectively enhance the apparent scattering at larger scattering angle relative to that at smaller scattering angle. It does not, however, change the position of the scattering maximum at about $2 \theta=14^{\circ}$, nor the relative $\beta^{\prime}$ s of the $14^{\circ}$ peaks from different samples, though the absolute values can vary somewhat. Because of this and the generally qualitative nature of the comparisons in this report we will restrict ourselves to simply normalizing the total number of counts from sample to sample. Should we decide to publish some of this data in the refereed literature a more complete analysis will be necessary.

\section{Samples With Different Thermal Histories.}

In the first set of experiments (K01-K33) we examined a number of different samples with the objective of determining whether we could see differences in the WAXS or SAXS for samples with different thermal histories. Included in this set of experiments were measurements on two samples (K06 - K07, K11 - K12, K29-K32) that had been drawn and thermally aged, discussion of these results will be included later with the discussion of the real time draw experiments, K53-K68.

Table I lists the samples examined, their thermal histories, and their DSC measured degrees of crystallinity (\% X), if measured, using a value of $43.1 \mathrm{~J} / \mathrm{g}$ for the $\Delta \mathrm{H}_{\text {fusion }}$ for "pure" crystalline material. Before aging, all samples except Kel-F 800, lot 702 , were initially taken far above $\mathrm{T}_{\mathrm{g}}$ and rapidly quenched to produce an amorphous material. Clearly in the case of PCTFE the rapidly quenched material is

Table I. List of samples with different thermal histories. The data sets in bold are the ones analyzed in detail.

\begin{tabular}{|c|c|c|c|}
\hline Sample & Thermal history & $\% \mathrm{X}$ & Data sets \\
\hline Kel-F 800, lot 639 & none & 0.1 & $\mathrm{~K} 19, \mathrm{~K} 27, \mathrm{~K} 28$ \\
\hline Kel-F 800, lot 639 & $40^{\circ} \mathrm{C}$ for $2.5 \mathrm{~d}$ & 3.5 & K22 \\
\hline Kel-F 800, lot 639 & $40^{\circ} \mathrm{C}$ for $10 \mathrm{~d}$ & 5.5 & K21 \\
\hline Kel-F 800, lot 639 & $60^{\circ} \mathrm{C}$ for $5.5 \mathrm{~h}$ & $4.6^{\#}$ & K23 \\
\hline Kel-F 800, lot 639 & $60^{\circ} \mathrm{C}$ for $21 \mathrm{~d}$ & $3.2^{\#}$ & $\mathrm{~K} 01, \mathrm{~K} 02, \mathrm{~K} 03, \mathrm{~K} 05, \mathrm{~K} 25, \mathrm{~K} 26$ \\
\hline Kel-F 800, lot 639 & $70^{\circ} \mathrm{C}$ for $11.6 \mathrm{~d}$ & 1.2 & K24 \\
\hline Kel-F 800 , lot $720^{*}$ & $40^{\circ} \mathrm{C}$ for $111 \mathrm{~h}$ & 7.8 & $\mathrm{~K} 08, \mathrm{~K} 09, \mathrm{~K} 10$ \\
\hline Kel-F 800, lot $720^{*}$ & $55^{\circ} \mathrm{C}$ for $16 \mathrm{~h}$ & 5.0 & $\mathrm{~K} 13, \mathrm{~K} 14$ \\
\hline Kel-F 800, lot 702 & ambient, $3.5 \mathrm{y}$ & 6.8 & $\mathrm{~K} 20$ \\
\hline pCTFE & none. & 11.4 & K17 \\
\hline PCTFE & $155^{\circ} \mathrm{C}$ for $1 \mathrm{~d}$ & & K18 \\
\hline pCTFE & $155^{\circ} \mathrm{C}$ for $17 \mathrm{~d}$ & 15.7 & $\mathrm{~K} 15, \mathrm{~K} 16$ \\
\hline
\end{tabular}


very crystalline, but note that elevated $\mathrm{T}$ aging increases the crystallinity. Samples were kept refrigerated after aging. The sample sets shown in bold are the ones actually analyzed in the text that follows. Where there were multiple measurements on a sample (generally different count times or different sample thicknesses) they showed excellent reproducibility in all cases where the sample allowed adequate transmission.

These samples were prepared as $\sim 1 \mathrm{~mm}$ thick films. This turned out to be unfortunate since although this might be an appropriate thickness for typical C, N, and $\mathrm{O}$ containing polymers, the significantly increased $\mathrm{x}$-ray opacity of $\mathrm{Cl}$ and to a lesser extent $F$ resulted in very limited transmission through full thickness samples. For this reason it was necessary to cut thin slivers of material from the samples for analysis. The thickness of these slivers is unknown and certainly varied from sample to sample. In Figure 3 I show for example the WAXS results (normalized as described above) from $1 \mathrm{~mm}$ thick pieces and thin slivers from two different samples. The Kel-F 800 sample is typical with complete loss of structure, the pCTFE sample, which may have been a little thinner and with much higher crystallinity shows the peak in both cases, but clearly the broad incoherent scattering that appears at high angle reduces the relative intensity of the peak significantly.

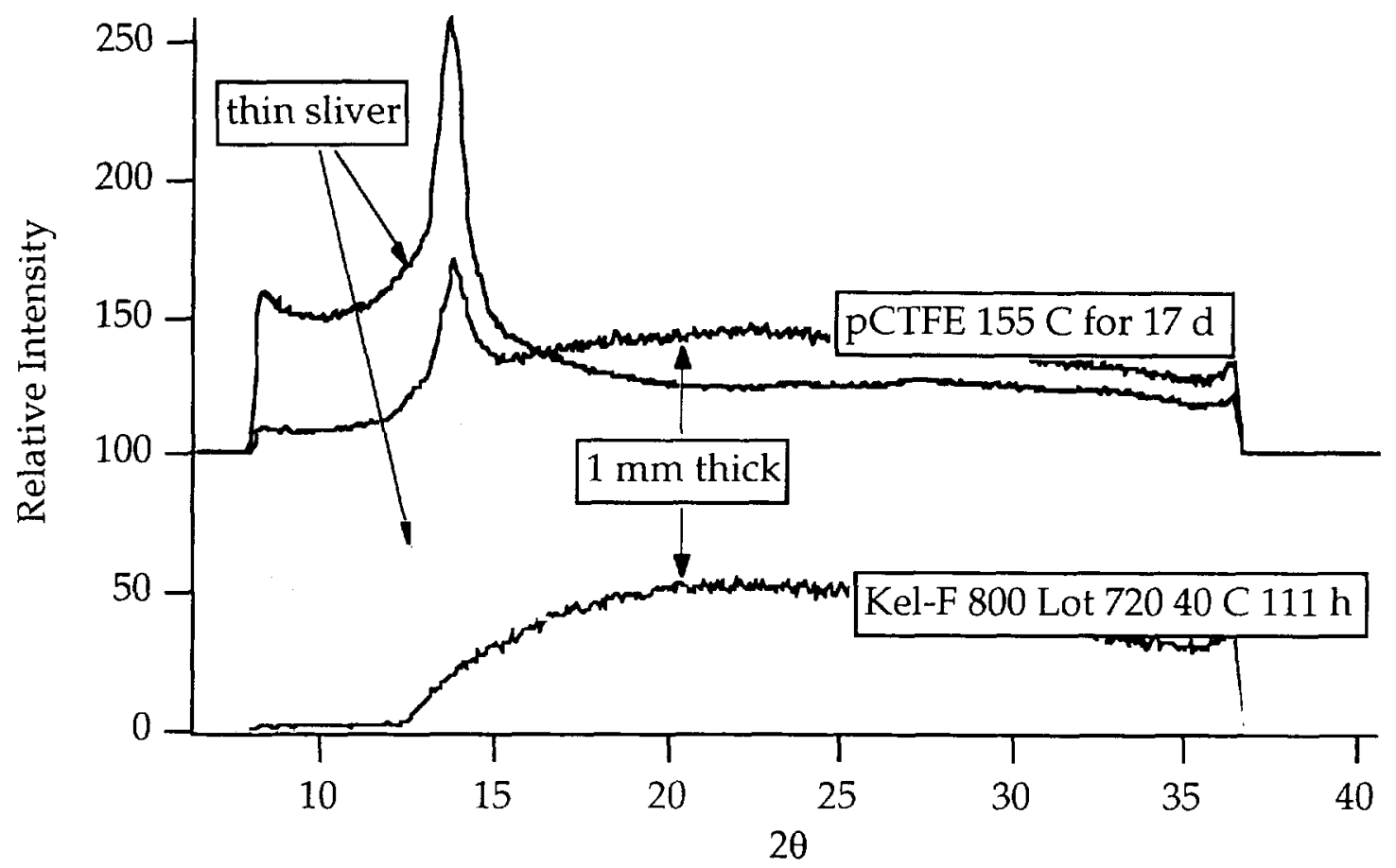

Figure 3. Examples of the problems with thick samples.

The appropriate thickness of the samples can be estimated as follows. ${ }^{6}$ The linear $\mathrm{x}$-ray absorption coefficient $\mu$ is defined in the standard way by

${ }^{6}$ L. E. Alexander, X-Ray Diffraction Methods in Polymer Science, Wiley-Interscience, New York, 1969, pp 26-28. 


$$
\frac{I}{I_{0}}=e^{-\mu t}
$$

where $I_{0}$ and $I$ are the incident and transmitted $X$-ray intensities and $t$ is the sample thickness, generally taken in $\mathrm{cm}$, thus the units of $\mu$ are $\mathrm{cm}^{-1}$. Thus in order to have the same relative transmission for a Kel-F 800 sample $(\mathrm{kf})$ as for a polyethylene sample (pe) it is necessary for

$$
\mu_{\mathrm{pe}} t_{\mathrm{pe}}=\mu_{\mathrm{kf}} t_{\mathrm{kf}} \text { or } t_{\mathrm{kf}}=\frac{\mu_{\mathrm{pe}}}{\mu_{\mathrm{kf}}} t_{\mathrm{pe}}
$$

$\mu$ is a function of both the atomic composition and material density, as well as the $x$ ray wavelength. Its values for individual elements are tabulated as mass absorption coefficients, $\mu / \rho$ (units of $\mathrm{cm}^{2} / \mathrm{g}$ ), so that it is useful to rewrite the equation above as

$$
t_{\mathrm{kf}}=\frac{(\mu / \rho)_{\mathrm{pe}}}{(\mu / \rho)_{\mathrm{kf}}} \cdot \frac{\rho_{\mathrm{pe}}}{\rho_{\mathrm{kf}}} \cdot t_{\mathrm{pe}}
$$

where the material mass absorption coefficient is given in terms of the individual atom mass absorption coefficients and their weight fractions, $w_{i}$, as

$$
\mu / \rho=\sum_{i} w_{i}(\mu / \rho)_{i}
$$

The values of $\mu \rho$ for $\mathrm{H}, \mathrm{C}, \mathrm{F}$, and $\mathrm{Cl}$ at $\lambda=1.307 \AA$ can be best approximated by the tabulated values at $1.295 \AA(\mathrm{Zn} \mathrm{K} \beta)$ which are $0.386,2.49,9.36$, and $66.7 \mathrm{~cm}^{2} / \mathrm{g}$, respectively. ${ }^{7}$ Thus if we compare polyethylene (empirical formula $\mathrm{CH}_{2}, w_{\mathrm{C}}=0.86$, $w_{\mathrm{H}}=0.14$ ) with Kel-F 800 (empirical formula $\mathrm{C}_{8} \mathrm{H}_{2} \mathrm{~F}_{11} \mathrm{Cl}_{3}, w_{\mathrm{C}}=0.23, w_{\mathrm{H}}=0.005, w_{\mathrm{F}}=$ $\left.0.51, w_{C l}=0.26\right)$ we find that $(\mu / \rho)_{\mathrm{pe}}=2.2$ while $(\mu / \rho)_{\mathrm{kf}}=22.5$. This coupled with a density difference of about a factor of two indicates that our samples should have been about $1 / 20$ the thickness of polyethylene samples, or perhaps about $50 \mu \mathrm{m}$ rather than $1 \mathrm{~mm}$.

The WAXS plots for the highlighted samples (all thin slivers) in Table I are displayed in Figure 4, and Table II summarizes their relevant features. All of the samples are characterized by a single relatively sharp peak at a value of $2 \theta$ between $13.64^{\circ}$ and $13.96^{\circ}$ which corresponds to $d_{W}$ values of between 5.50 and $5.38 \AA$. Peak width measurements give Scherrer lengths, $L$, of from 32 to $56 \AA$ for the Kel-F 800 samples, with larger values for the more highly crystallized pCTFE samples. To

\footnotetext{
${ }^{7}$ Handbook of Chemistry and Physics, 58th ed, R. C. Weast, ed., 1978, p E-139.
} 


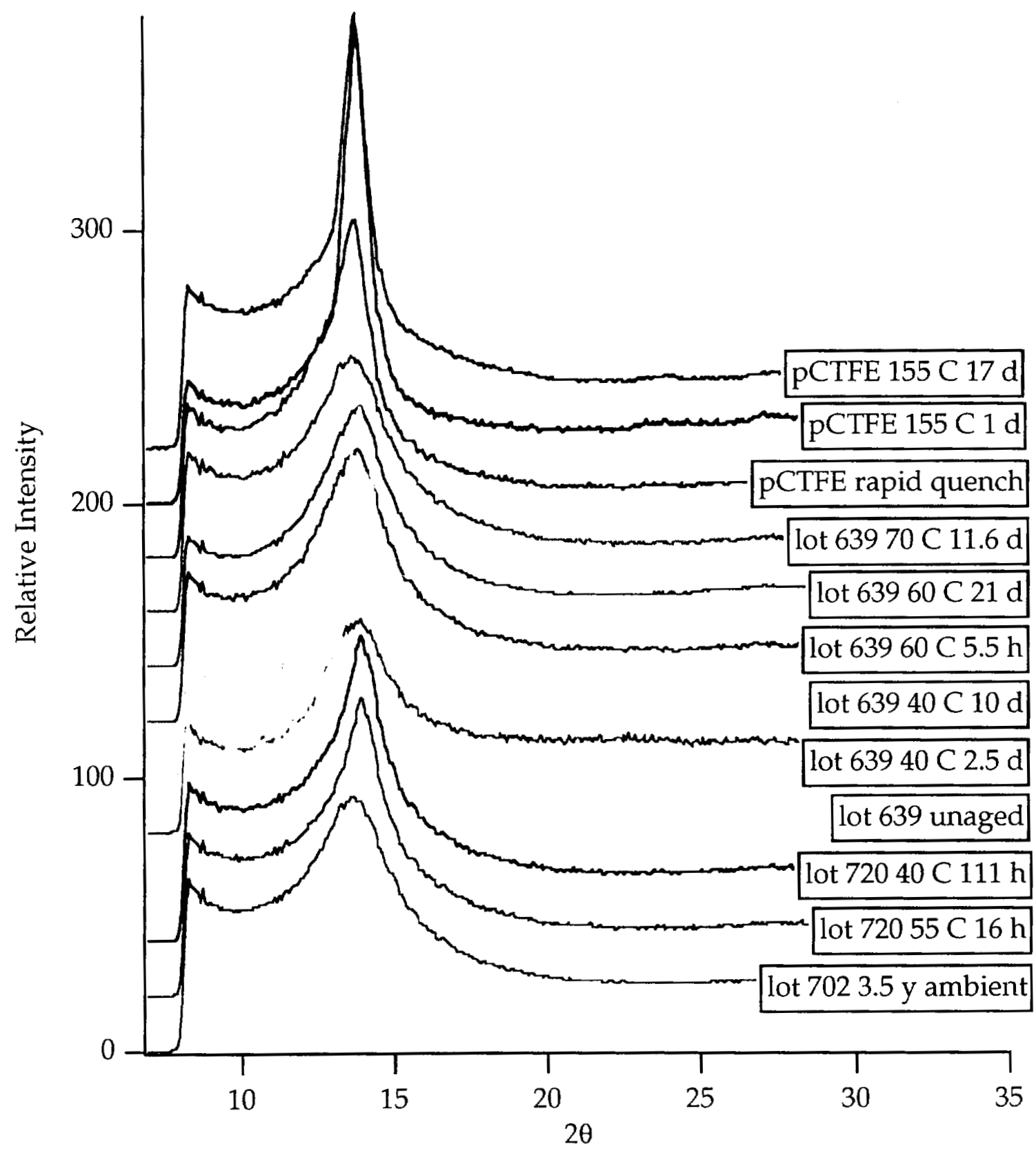

Figure 4. WAXS data for thermally aged samples. Data has been scaled to equal numbers of counts, and successive traces translated upward by 20 intensity units.

zeroth order the peak maxima are probably indistinguishable, especially given the variation in sample thicknesses that gives rise to different amounts of diffuse scattering at low angle. This is clear in Figure 4 where one can see that to the right of the peak the scaled curves (except lot $63940 \mathrm{C} 2.5 \mathrm{~d}$ ) are evenly spaced by the vertical displacement (20 intensity units), but to the left of the peak the intensities vary from sample to sample. A plot of $d_{W}$ (red circles, left axis) and $L$ (blue squares, right axis) as a function of crystallinity for the Kel-F samples is shown in Figure 5 
Table II. Summary of WAXS results for thermally aged samples.

Sample

Kel-F 800, lot 639

Kel-F 800, lot 639

Kel-F 800, lot 639

Kel-F 800, lot 639

Kel-F 800, lot 639

Kel-F 800, lot 639

Kel-F 800, lot $720^{*}$

Kel-F 800, lot 720*

Kel-F 800, lot 702

pCTFE

PCTFE

pCTFE
Thermal history none

$40^{\circ} \mathrm{C}$ for $2.5 \mathrm{~d}$

$40^{\circ} \mathrm{C}$ for $10 \mathrm{~d}$

$60^{\circ} \mathrm{C}$ for $5.5 \mathrm{~h}$

$60^{\circ} \mathrm{C}$ for $21 \mathrm{~d}$

$70^{\circ} \mathrm{C}$ for $11.6 \mathrm{~d}$

$40^{\circ} \mathrm{C}$ for $111 \mathrm{~h}$

$55^{\circ} \mathrm{C}$ for $16 \mathrm{~h}$

ambient, $3.5 \mathrm{y}$

none

$155^{\circ} \mathrm{C}$ for $1 \mathrm{~d}$
$\% X$

0.1

3.5

5.5

$4.6^{\#}$

$3.2^{\#}$

1.2

7.8

5.0

6.8

26.5

31.9

36.5
$2 \theta_{\max } \underline{d}_{w}(\AA)$

$13.65 \quad 5.50$

$13.80 \quad 5.44$

$13.92 \quad 5.39$

$13.78 \quad 5.45$

13.86

13.64

13.96

13.96

13.75

13.70

13.79

13.75

$\underline{\beta(\operatorname{deg}) \quad L(\AA)}$

$2.10 \quad 36$

$2.34 \quad 32$

$1.40 \quad 54$

$2.07 \quad 37$

$2.11 \quad 36$

$2.13 \quad 35$

$1.37 \quad 55$

$1.35 \quad 56$

$2.14 \quad 35$

$1.47 \quad 51$

$0.91 \quad 83$

* - Sample aged ambient for 3 y before elevated $\mathrm{T}$ aging

\# - DSC scans questionable

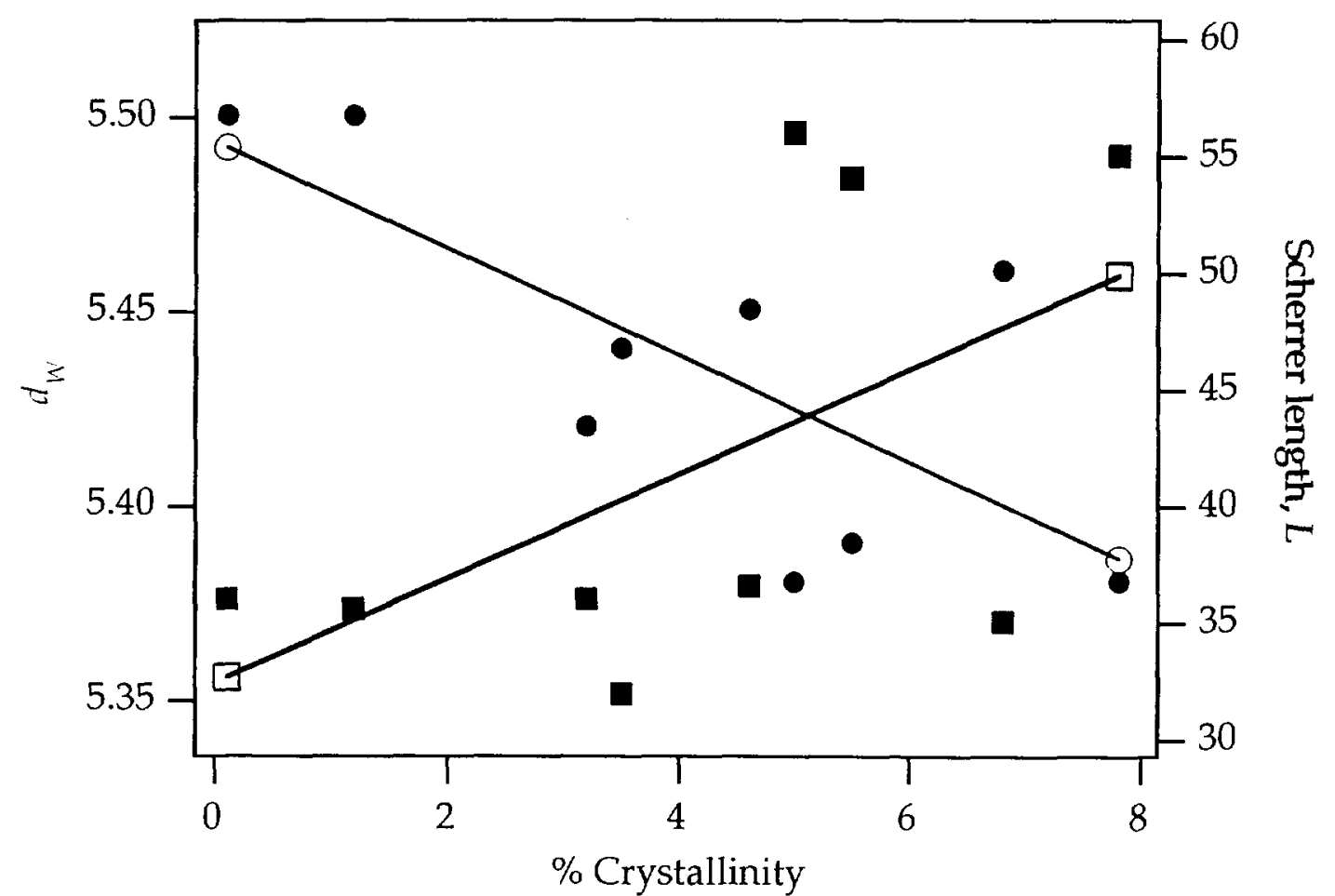

Figure 5. Plot of $d_{W}$ (left axis, red circles) and $L$ (right axis, blue squares) as a function of crystallinity for Kel-F 800 samples. The lines are least square fits.

The lines with open symbols on the ends are linear fits. One might possibly argue there is a weak correlation between crystallinity and $d_{W}$, the more highly crystalline 
samples showing slightly smaller values, but there is clearly no arguable correlation between the Scherrer length, $L$, and Kel-F 800 crystallinity seen in this data. This latter fact is a little surprising since one might expect some average increase in the local order for partially crystalline samples, but it may be that the level of crystallinity is simply too low. For the pCTFE samples with much higher degrees of crystallinity the Scherrer length is markedly longer, as are the relative intensities of these peaks compared to the Kel-F 800 samples. Of the Kel-F 800 samples the Lot 639 aged at $40^{\circ} \mathrm{C}$ for 10 days $(\% \mathrm{X}=5.5)$ and to a lessor extent the Lot 720 aged samples $(\% X=7.8$ and 5.0$)$ have relatively higher intensities than the other Kel-F 800 samples. Thus there may be some demonstrated correlation between relative peak height and degree of crystallinity, but it is at best qualitative.

Perhaps the most significant result for these samples is that there is no evidence of crystalline structure in the peak such as has been reported in the

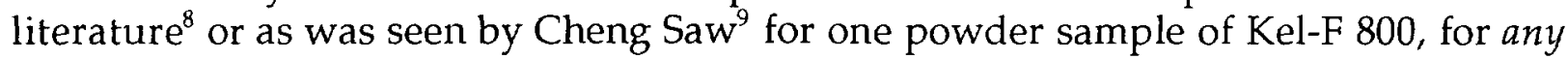
of the samples, including the pCTFE which was as high as $36 \%$ crystalline as determined by DSC. The absence of structure is troublesome. Resolution could have been improved by moving the detector away from the sample in such a fashion to spread out the data collection over a narrower $2 \theta$ range. However the detector was certainly sensitive enough to reveal structure had it been present, and the best that I can conclude is that the nature of the crystallinity, particularly in the Kel-F 800 samples, was very imperfect giving rise only to a small contribution to a large amorphous peak which exists at the same location. Given this situation it seems unlikely that WAXS is going to provide a useful method for determining any information about the degree of crystallinity in these samples.

The SAXS results for the samples highlighted in Table I are shown in Figure 6. The raw data have been normalized by dividing by the total number of counts, and then the traces have been displaced vertically on the log scale by multiplication by factors of 2 . Note that all traces appear essentially identical in form, though the details of the noise are different in each. At the top I have added the SAXS from the blank (K33) and also the SAXS from the first sample run (K01) which is the same material as the lot $639-60^{\circ} \mathrm{C}-21 \mathrm{~d}$ samples that were run later $(\mathrm{K} 03, \mathrm{~K} 05, \mathrm{~K} 25, \mathrm{~K} 26)$. Note first that the blank is identical to all the data below it, suggesting that there is no small angle scattering from the sample. However also note that the SAXS for sample $\mathrm{K} 01$ is distinctly different near $\mathrm{q}=0$, rising to its maximum more rapidly. SAXS from later samples (after K33) have the same general appearance as will be seen later when those data sets are discussed. The SAXS for sample K02 is of the same form as K01 (it was the same sliver with longer collection time), but after that nearly all SAXS results in the first set of experiments (K01 to K33) are essentially identical, including the little squiggle at about $q=0.06$. The only exceptions are the drawn and aged samples measured with the draw direction parallel to the detector

\footnotetext{
8 A. Siegmann, G. Cohen, and Z. Baraam, J. Appl. Polym. Sci. 37, 1567 (1989).

9 Cheng Saw, "Interim report on the Examination of Crystallinity in Annealed Kel-F 800 Powders," internal memo \# CKS/99/08, June 4, 1999.
} 
(samples $\mathrm{K} 07, \mathrm{~K} 12, \mathrm{~K} 31, \mathrm{~K} 32$ ) which look a little different at the intensity maximum. These samples are discussed later. It is possible that the sliver used for $\mathrm{K} 01$ and $\mathrm{K} 02$ had some unusual feature making it different from the others. However the only conclusion that I can draw from the small angle results is that perhaps the data is faulty for some reason and/or there are no interesting features.

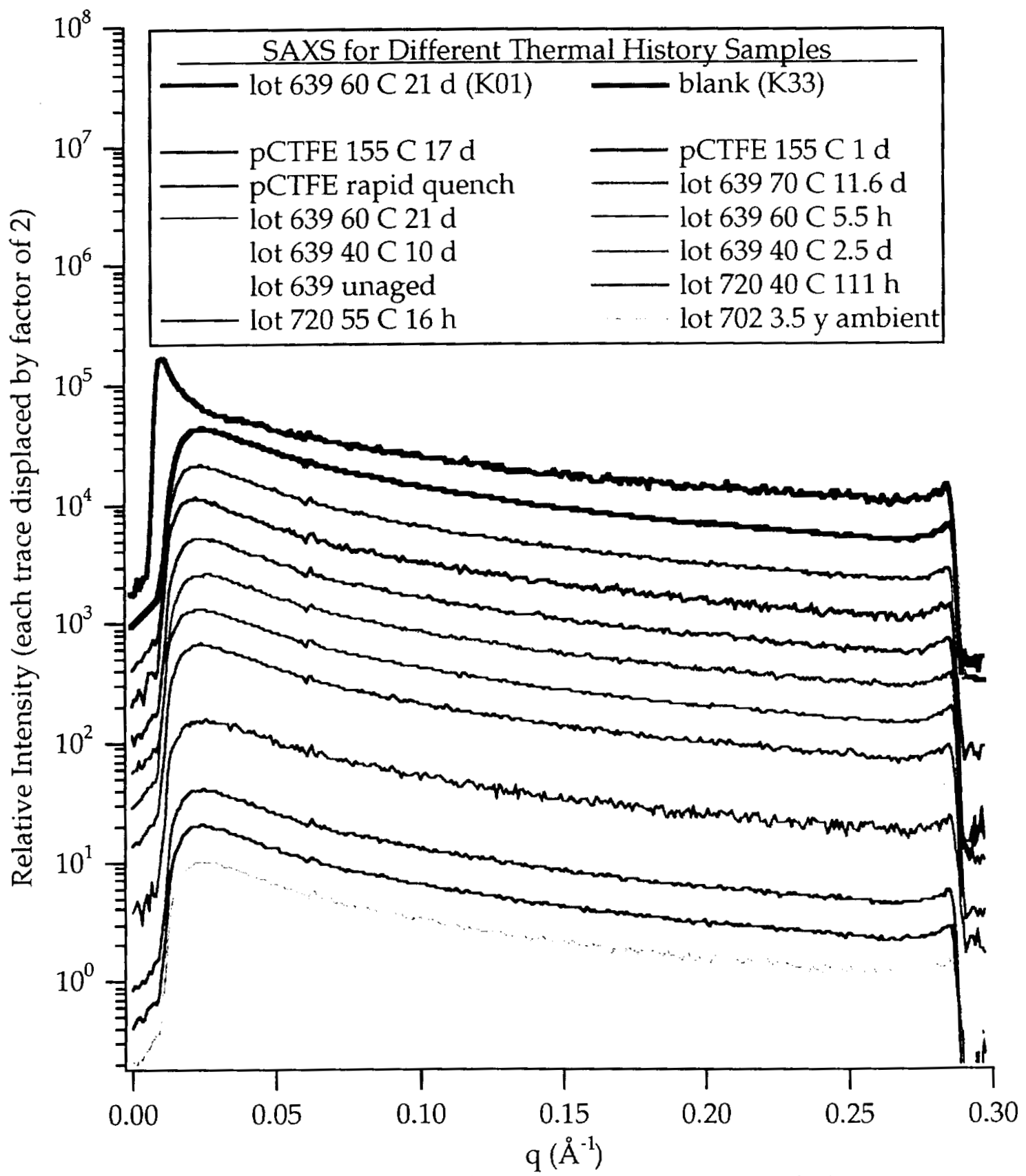

Figure 6. SAXS results for samples listed in Table II. Added to the top are the blank, which is identical to the traces below it, and the first sample, K01. 


\section{Temperature Dependence Studies.}

A series of experiments were conducted on Kel-F 800 at elevated temperature. The initial purpose of these studies was to determine if the structure responsible for the $5.6 \AA$ peak would fade away at elevated temperature. Such would be the case if the peak was due to a local helical order along the polymer backbone.

Amorphous Kel-F 800 samples prepared from Lot 639 were used. A small piece of polymer film about $1 \mathrm{~mm}$ thick and about $5 \mathrm{~mm}$ square was cut and pressed into a $\mathrm{Cu}$ holder as shown in Figure 7. Pieces of very thin Kapton tape were applied on the front and back sides to hold it in place. Scattering curves for just the Kapton tape on the $\mathrm{Cu}$ sample holder and a true blank with no tape or sample showed no significant differences. The $\mathrm{Cu}$ holder was then inserted into a heating device in the beam line and heated to the desired temperature.

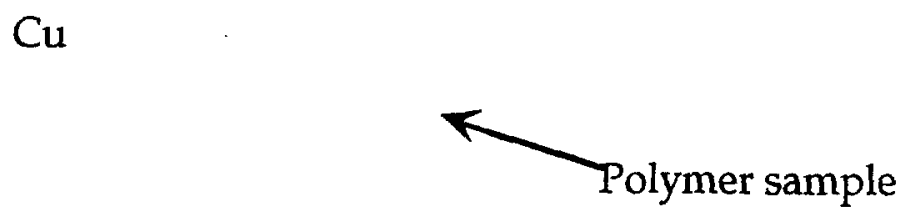

Figure 7. Sample holder for temperature dependence experiments.

In the first set of experiments (K34 to $\mathrm{K} 41$ ) the temperature was taken up to $200{ }^{\circ} \mathrm{C}$ and held there while 3 separate $120 \mathrm{~s}$ data collections were taken, and then cooled down to $30{ }^{\circ} \mathrm{C}$ and remeasured. In addition to the $200{ }^{\circ} \mathrm{C}$ data $120 \mathrm{~s}$ collections were also taken during the ramp up, specifically between 40 and $92{ }^{\circ} \mathrm{C}$ and 120 to $172{ }^{\circ} \mathrm{C}$. The data for these samples is presented in Figure 8, individual scans being offset vertically for clarity. Clearly one can see that a) the maximum in the peak moves to smaller angle (larger distance) as the temperature is increased due to thermal expansion b) that the peak width broadens somewhat at elevated temperature indicating a slight degradation in the atomic correlation that produces the peak and c) that cooling the sample essentially allows one to recover the initial $25^{\circ} \mathrm{C}$ trace, though a careful analysis shows that a little intensity is shifted to lower angle. Visual examination of the cooled sample showed that it had melted and flowed somewhat, it uniformly filled the circular opening in contrast to the picture in Figure 7, and it had a number of small gas bubbles trapped in it.

Following this initial trial the experiment was repeated with a new sample of the same material with the objective of more precisely collecting data at temperatures below $200^{\circ} \mathrm{C}$ as well as collecting data at higher temperatures. The results are presented in Figure 9. The same basic trends reported above are seen. It was noted during the measurement at 250 and $300^{\circ} \mathrm{C}$, and to a lesser degree at 200 ${ }^{\circ} \mathrm{C}$, that the transmitted intensity (recorded in real time on the computer monitor) varied significantly during the $120 \mathrm{~s}$ run, probably indicating changes in sample 


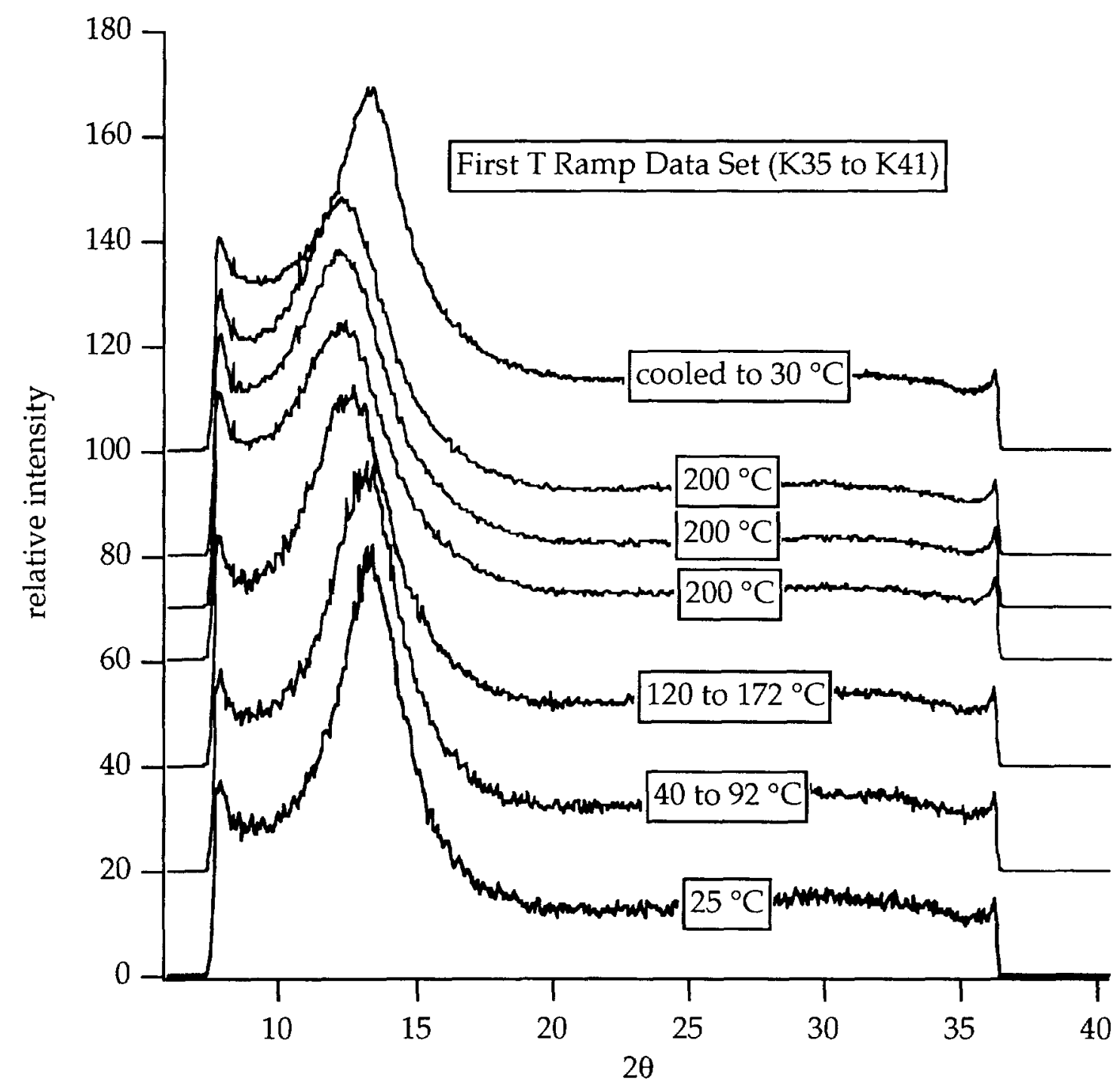

Figure 8. Data from first set of temperature dependence experiments.

thickness due to flow of the fluid sample as well as possible bubble formation. An attempt to obtain a second $300{ }^{\circ} \mathrm{C}$ scan on the sample (run K50) gave no scattered signal, examination of the sample holder after cooling showed no sample in the center of the opening. It is likely that the relative shift of intensity to lower angle seen in the high temperature runs may be in part due to this sample thinning. However the shift of maximum peak intensity and the peak broadening are indicative of thermal expansion and loss of correlation. 


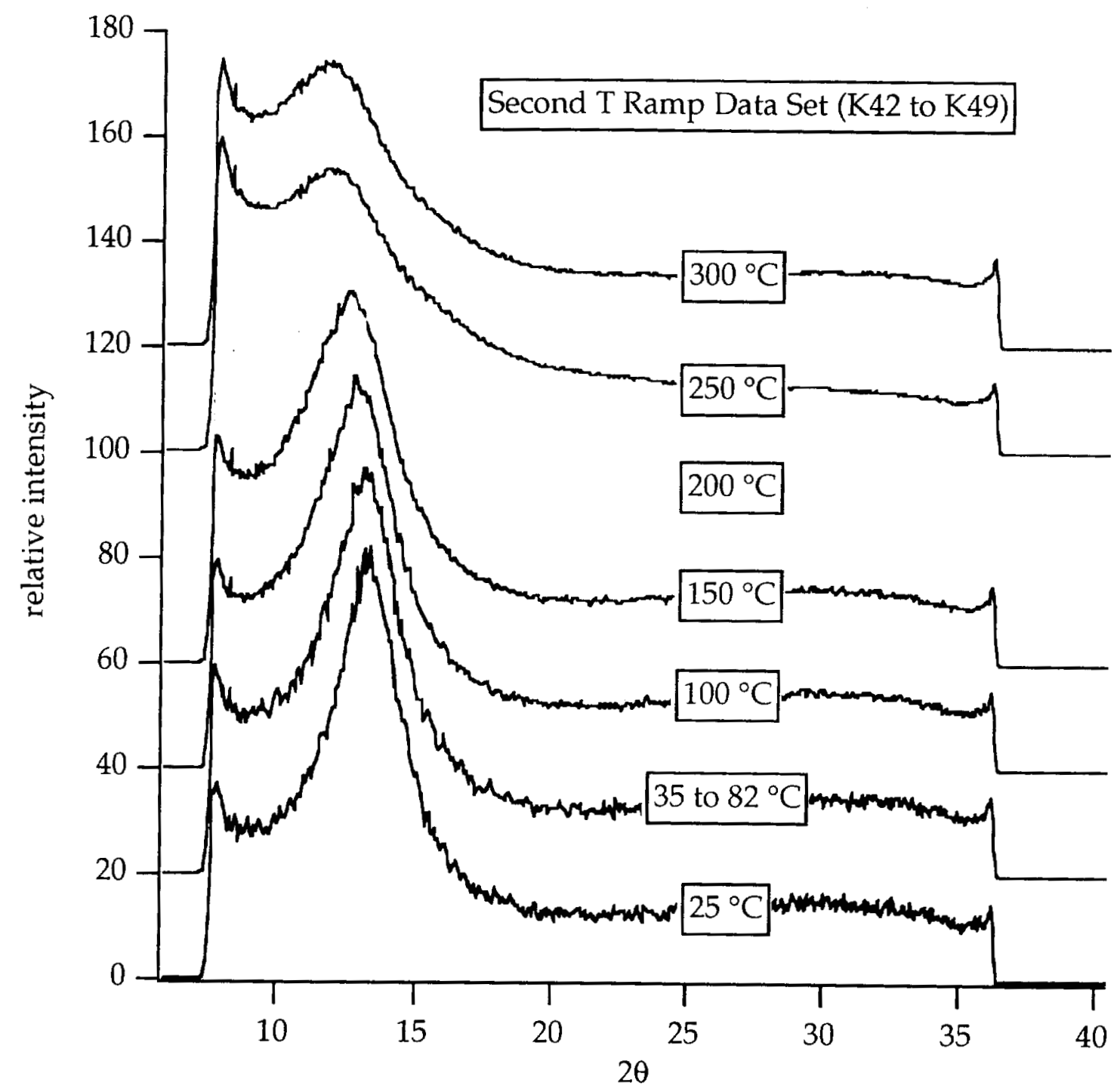

Figure 9. Data from second set of temperature dependence experiments.

The data in Figure 9 was smoothed and the angle of maximum intensity determined. From this one can determine the primary correlation length, $d$, (in a crystalline system the distance between scattering planes) from the Bragg equation $(\lambda=1.307 \AA)$ :

$$
d=\frac{\lambda}{2 \sin \theta}
$$

The results are in Table III. 
Table III. Correlation length at maximum scattering intensity as a function of temperature for the data in Figure 9.

\begin{tabular}{rrrrrrr}
$T\left({ }^{\circ} \mathrm{C}\right)$ & \multicolumn{1}{c}{25} & \multicolumn{1}{c}{100} & \multicolumn{1}{c}{150} & \multicolumn{1}{c}{200} & \multicolumn{1}{c}{250} & \multicolumn{1}{c}{300} \\
\hline $2 \theta$ & 13.33 & 12.90 & 12.62 & 12.26 & 11.90 & 11.76 \\
$d(\AA)$ & 5.63 & 5.82 & 5.95 & 6.12 & 6.30 & 6.38 \\
\hline
\end{tabular}

In Figure 10 we plot $d / d_{25}{ }^{\circ} \mathrm{C}$ as a function of temperature, the slope of the line through the data is the linear coefficient of thermal expansion, LCTE, and is found to be equal to $5.07 \times 10^{-4}{ }^{\circ} \mathrm{C}^{-1}$. Cady and Caley ${ }^{10}$ report a value of 3 to $16 \times 10^{-4}{ }^{\circ} \mathrm{C}^{-1}$ for Kel-F 800 above $T_{g}$. It is worth noting that most polymers have a LCTE of from 5 to $7 \times 10^{-4}{ }^{\circ} \mathrm{C}^{-1}$ above $\mathrm{T}_{\mathrm{g}}{ }^{11}$ and our results are consistent with this observation.

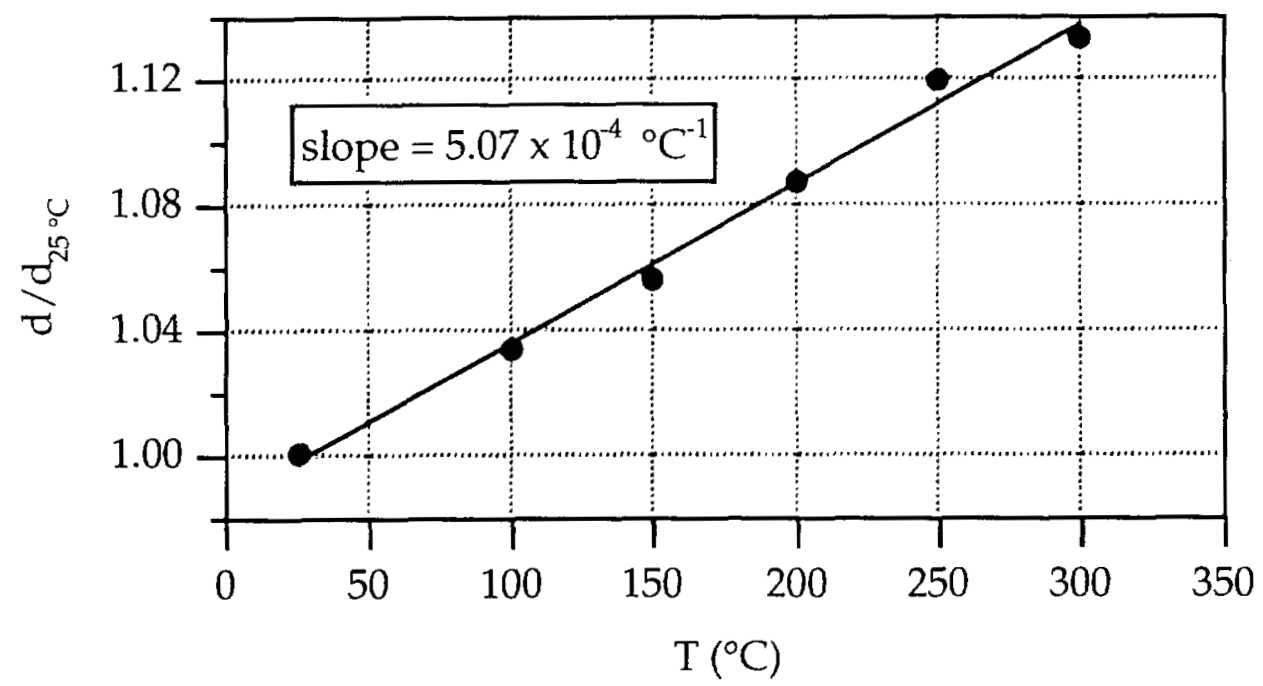

Figure 10. Shown is a plot of scattering correlation length relative to the value at $25^{\circ} \mathrm{C}$ at maximum intensity, as a function of temperature.

Using this information we can also state that the density as a function of temperature over this range is given by

$$
\rho(T)=\frac{\rho\left(25^{\circ} \mathrm{C}\right)}{(1+(.000507)(T-25))^{3}}
$$

where $\mathrm{T}$ is measured in ${ }^{\circ} \mathrm{C}$.

\footnotetext{
${ }^{10}$ W. E. Cady and L. E. Caley, Properties of Kel-F 800 Polymer, LLNL UCRL-52301 (1977), as reported in Polymeric Materials, p 235, compiled by B. Dobratz, LLNL M-088, June 30, 1978.

${ }^{11}$ J. E. Mark, Physical Properties of Polymers Handbook, American Institute of Physics, Woodbury, NY, 1996, Table 7.4, p 85.
} 
SAXS data were taken simultaneously for each experimental condition. For most of these runs the thick samples resulted in relatively little transmission and thus the total number of counts for each experimental condition was both small, leading to large scatter, and also varied, particularly for the hotter samples that were thinning. To compare the different conditions in Figure 11 the data has been scaled by dividing the number of counts at each $\mathrm{q}$ for a data set by the total SAXS counts for that sample condition. Each normalized set was then multiplied by 2000 to produce the normalized intensity plots in Figure 11. The superposition of the data makes it difficult to see any detailed differences, but it is safe to say there are no dramatic differences.

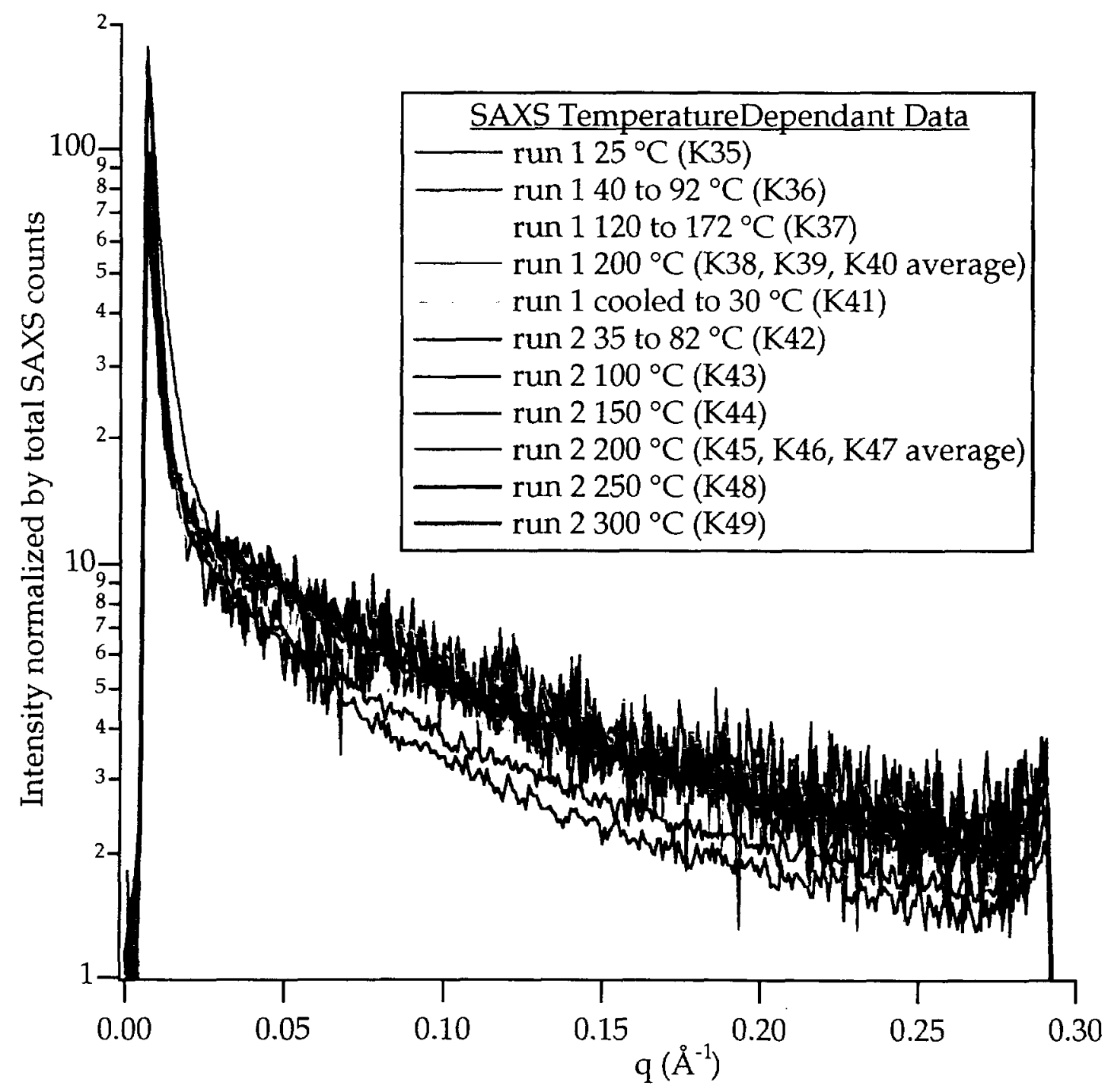

Figure 11. Normalized SAXS temperature dependant data.

To more carefully examine the detail, the data in Figure 11 was separated vertically by multiplying the individual scaled data sets by successive powers of 2 . 
The resulting data is presented in Figure 12, where for some of the data sets I have placed a black dotted line through the data that represents the multipass box smoothing of the data. Note that there appears to be some structure in the lower temperature Run 1 data (bottom 2 or 3 traces). This was first noted by Cheng Saw in his memo, however I believe it must be an artifact of the sample (or sampling).

First note that as the $T$ is raised for the run 1 data the structure disappears, and does not reappear after the sample is cooled. Second, in run 2 no similar structure is seen in the lower $\mathrm{T}$ runs $\left(35\right.$ to $82^{\circ} \mathrm{C}$ or $100^{\circ} \mathrm{C}$ ). Thus I think it is reasonable to conclude that the apparent structure in the low temperature Run 1 sample is a result of a combination of poor statistics and perhaps also some kind of small defect on the surface that melts away on the Run 1 sample as the $T$ is raised.

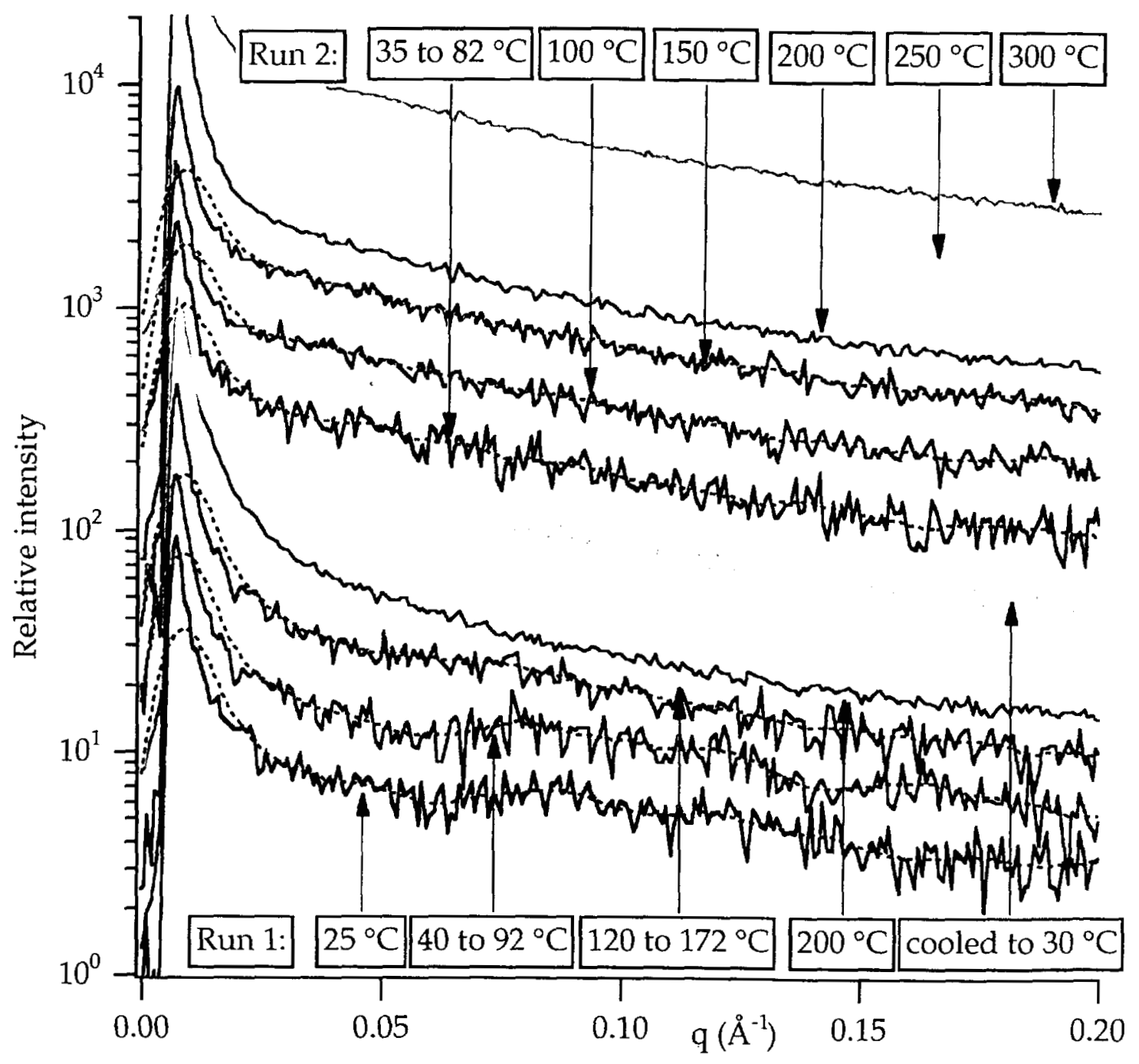

Figure 12. Vertically displaced scaled SAXS data for temperature dependent runs. 


\section{Oriented Samples.}

In this section we will examine the results obtained for drawn and oriented samples. Two kinds of experiments were conducted. In the first case two dog bone samples of Kel-F 800 were drawn to approximately $300 \%$ and then aged in the drawn state at 40 and $55{ }^{\circ} \mathrm{C}$ for 111 and $16 \mathrm{~h}$, respectively, to enhance crystallization. The centers of these samples (which had been kept cold until the time of measurement) were cut out and the scattering both perpendicular and parallel to the draw direction was measured with the linear detector. In the second case initially amorphous Kel-F 800 samples at ambient temperature were drawn in real time to different extents. The drawing device simply clamped a dog bone sample and then the distance between the clamps could be increased with a simple screw mechanism. The $x$-ray beam was passed through the center of the clamped and drawn dog bone as shown schematically in Figure 13. Unfortunately the drawing device did not allow for measurement parallel to the draw direction for clamped samples.

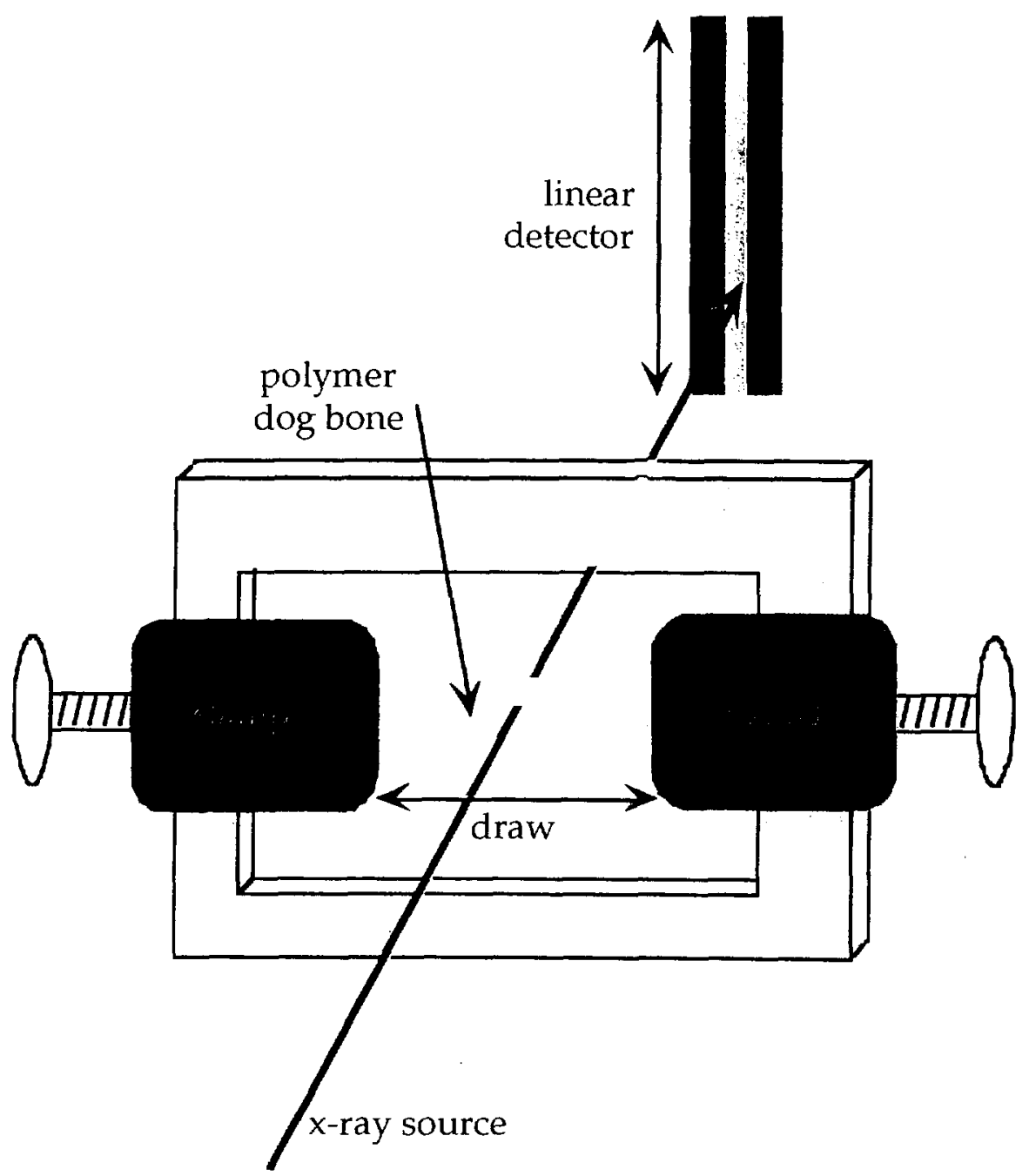

Figure 13. Real time draw apparatus. Note sample draw direction is perpendicular to linear detector. 
Table IV. List of samples. All are Kel-F 800, Lot 720, and were supplied by Steve DeTeresa. For the unaged samples the draw factor (DF) is defined as the drawn length between clamps divided by the initial length. The data sets in bold are the ones analyzed in detail.

\begin{tabular}{lll} 
Draw condition & Thermal history & Data sets \\
\cline { 2 - 3 } undrawn & $40^{\circ} \mathrm{C}$ for $111 \mathrm{~h}$ & $\mathrm{~K} 08, \mathrm{~K} 09, \mathrm{~K} 10$ \\
$300 \%$ perpendicular & $40^{\circ} \mathrm{C}$ for $111 \mathrm{~h}$ & $\mathrm{~K} 06, \mathrm{~K} 29, \mathrm{~K} 30$ \\
300\% parallel & $40^{\circ} \mathrm{C}$ for $111 \mathrm{~h}$ & $\mathrm{~K} 07, \mathrm{~K} 31, \mathrm{~K} 32$ \\
\hline undrawn & $55^{\circ} \mathrm{C}$ for $16 \mathrm{~h}$ & $\mathrm{~K} 13, \mathrm{~K} 14$ \\
$300 \%$ perpendicular & $55^{\circ} \mathrm{C}$ for $16 \mathrm{~h}$ & $\mathrm{~K} 11$ \\
300\% parallel & $55^{\circ} \mathrm{C}$ for $16 \mathrm{~h}$ & $\mathrm{~K} 12$ \\
undrawn & none & $\mathrm{K} 53$ \\
DF $=2.0$ & none & $\mathrm{K} 54$ \\
$\mathrm{DF}=3.0$ & none & $\mathrm{K} 55$ \\
$\mathrm{DF}=3.3$ & none & $\mathrm{K} 56$ \\
$\mathrm{DF}=3.7$ & none & $\mathrm{K} 57$ \\
$\mathrm{DF}=4.0$ & none & $\mathrm{K} 58$ \\
$\mathrm{DF}=4.3$ & none & $\mathrm{K} 59$ \\
$\mathrm{DF}=4.7$ & none & $\mathrm{K} 60$ \\
$\mathrm{DF}=3.0$ & none & $\mathrm{K} 61$ \\
$\mathrm{DF}=6.0$ & none & $\mathrm{K} 62$ \\
$\mathrm{DF}=8.0$ & none & $\mathrm{K} 63$ \\
$D F=10.0$ & none & $\mathrm{K} 64$ \\
$\mathrm{DF}=12.0$ & none & $\mathrm{K} 65$ \\
$\mathrm{DF}=14.0$ & none & $\mathrm{K} 66$ \\
$\mathrm{DF}=20.0$ & none & $\mathrm{K} 67$ \\
$\mathrm{DF}=35.0$ & none & $\mathrm{K} 68$
\end{tabular}

The samples discussed in this section are listed in Table IV. For the real time draw samples the draw factor (DF) is defined as the drawn distance between clamps divided by the initial (undrawn) distance between clamps. Three samples were tested in this fashion, with increasingly smaller initial distances to allow for greater draw factors. Each sample thus produced a set of data at each of several DF's. It was clear in each case that the draw was not uniform and thus at best the sequence of measurements in a given set represented increasing degrees of draw. In the case of the last experiment $(\mathrm{K} 68)$ the center of the sample turned white, perhaps indicating spontaneous crystallization, though nothing in the WAXS or SAXS would confirm this.

The purpose of these experiments on oriented samples was to attempt to determine the origin on the sharp scattering peak at about $2 \theta=14^{\circ}$. By drawing the samples we tend to align and orient the chains. Thus scattering seen parallel to the draw direction can be interpreted as structure in that direction, which might be interpreted as intra-chain order. Scattering perpendicular to the draw direction must be due to correlations between chains, a manifestation of inter-chain order. 
The results for the two samples that were thermally aged while drawn are shown in Figure 14. Both samples tell the same story. The undrawn and aged scattering is nearly identical for the two samples and typical for partially crystalline (as well as amorphous!) Kel-F 800 samples. For the drawn samples the scattering perpendicular to the draw direction is significantly enhanced while the scattering parallel to the draw direction is almost completely suppressed. In contradistinction to my earlier suggestion that a helical chain backbone in an otherwise amorphous polymer might be the origin of the relatively sharp scattering seen in amorphous samples, ${ }^{12}$ these results are a clear indication that there is no intra-chain structure along the chain backbone, instead the only structure giving rise to the scattering is inter-chain.

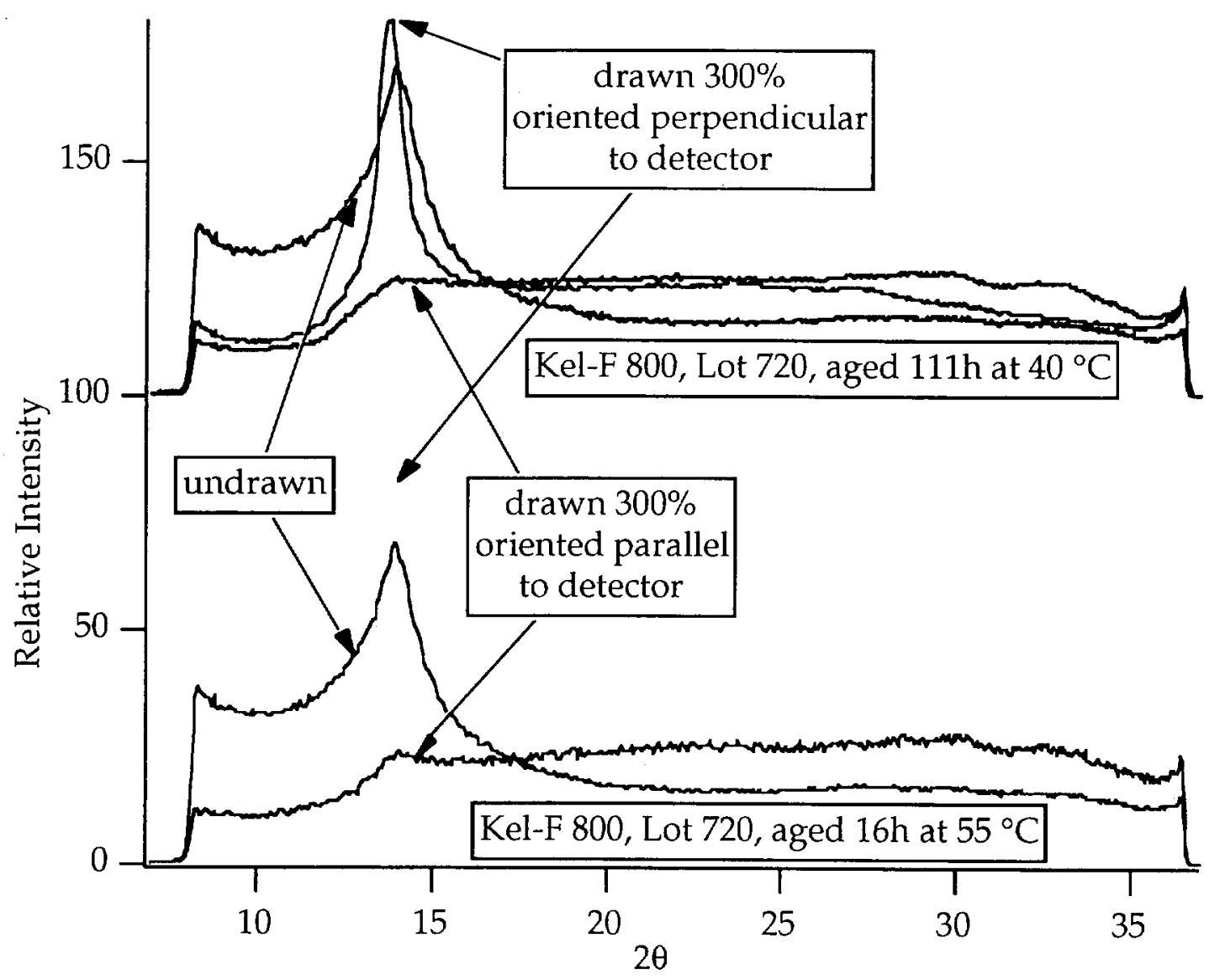

Figure 14. WAXS of drawn and aged Kel-F 800 samples.

The small angle scattering for these samples does show a small difference depending upon orientation. The data (scaled with the upper set offset by a factor of

\footnotetext{
${ }^{12}$ Bob Cook, "Some Thoughts on Kel-F 800 Crystallization," internal memo dated February 16, 1999; Bob Cook, "Experimental Plans for August 11-13 X-Ray Scattering Experiments at Brookhaven National Lab," internal memo dated June 25, 1999.
} 
2 ) is displayed in Figure 15 over a narrow $q$ range around the maximum. The plot shows that over the $q$ range from about 0.02 to $0.05 \AA^{-1}$ the scattering in the parallel orientation shows a small increased intensity relative to the perpendicular direction, which is the same as the undrawn material. Note this is the reverse of the WAXS results. There are no other distinguishing features in the SAXS at higher $q$. From eq 2 the $q$ range from 0.02 to 0.05 represents a correlation length of from 315 to $125 \AA$. It is certainly unclear to me the significance of this difference, the only correlation I can imagine in the chain direction with repeat length in the range of 125 to $315 \AA$ might be something related to molecular weight, perhaps an irregular clustering of chain ends? Another possibility might be the lengths of individual crystals, the computed Scherrer length $L$ from the perpendicular WAXS is about 100 $\AA$, but presumably this would be a length in the perpendicular direction. Thus at this point the best I can do is point to the feature and move on.

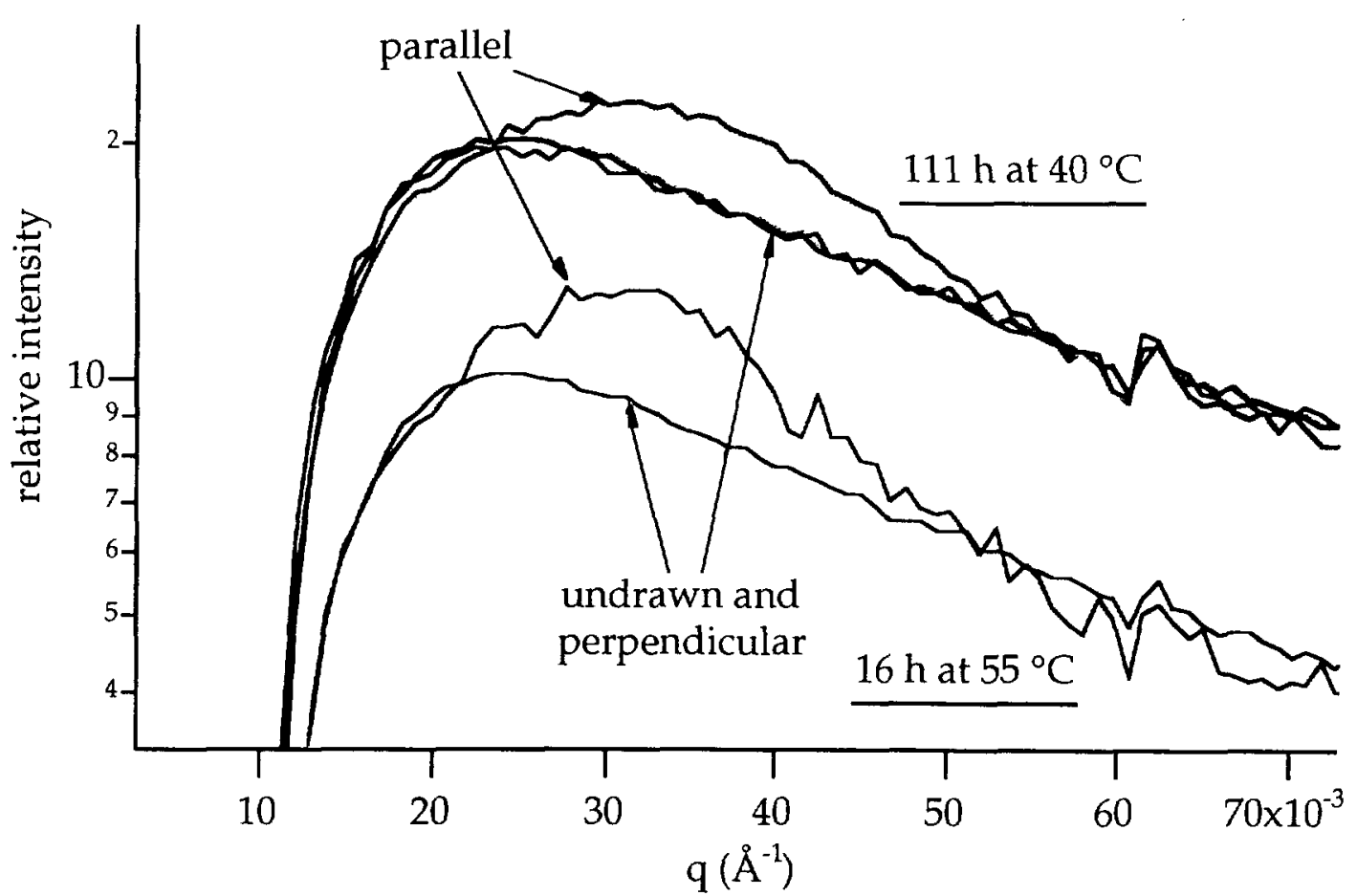

Figure 15. SAXS at peak intensity for drawn and aged Kel-F 800 samples.

The remaining experiments to be discussed are the real time draw experiments. Unlike the samples discussed above, the expectation is that for the real time draw experiments the initially amorphous state of the material would be maintained (though oriented) and that no crystallization would take place during the draw at room temperature. As noted above, the last sample (K68) under extreme draw may have spontaneously crystallized, there was no visual indication that any of the other ones did. However DSC was not performed on these samples after draw so we have no verification that some degree of crystallization did or did not take place. An additional problem with these experiments is that unlike the 
drawn and aged samples discussed above, only scattering perpendicular to the draw direction was measured and thus no information exists about scattering along the draw direction.

The unscaled (but for two sets vertically displaced)WAXS scattering perpendicular to the draw direction is shown in Figure 16 for the three sets of experiments listed in Table IV. In each case the amplitude of the main peak increases with increasing draw factor. It is tempting to assign the apparent sharpening of the peak to increased order, however this may not be the case. The initial dog bone samples were about $1 \mathrm{~mm}$ thick, and in the undrawn state there was relatively little transmission. The bottom blue trace is for the undrawn sample (K53) and the primary scattering peak which is seen clearly in thinner samples is completely absent. As the sample is drawn it becomes thinner, and it is possible that what we are seeing as increased scattering intensity is primarily due to the thinner samples. For this reason alone it would be very valuable to have the scattering in the draw direction also, so that the relative intensities in the two directions could be compared. Perhaps such an experiment can yet be done here at LLNL. But in the absence of this data it is difficult to unambiguously interpret the increased intensity with draw factor. One piece of evidence that is consistent with the view that all we are seeing is a thinning sample is that the peak widths at half height are not changing. This is in contrast to the data on the drawn and aged samples where the Scherrer length increased by about a factor of two between the aged undrawn and drawn samples.

Lastly the SAXS data for these samples have no distinguishing characteristics, with the exception of slightly increased overall intensity with high DF (and thus thinner) samples. The data is not shown, in part because it is not distinctive and in part because lack of time prevented our getting a SAXS calibration run. This latter factor is of little significance since it only has the effect of moving the data slightly in q space.

\section{Acknowledgements.}

The results presented here are in fact the result of the efforts of many people. Pat Lewis prepared the thermally aged samples and Randy Weese provided DSC characterization. Steve DeTeresa provided the oriented and aged samples, as well as the real time draw apparatus. Sam Gido at the University of Massachusetts provided valuable advice in suggesting the oriented sample experiments. Fengji Yeh, the staff scientist supporting the Advanced Polymer Beamline at Brookhaven provided essential assistance in performing the experiments. Cheng Saw likewise was essential in the execution of the experiments and has also helped me to understand aspects of the results since returning. 


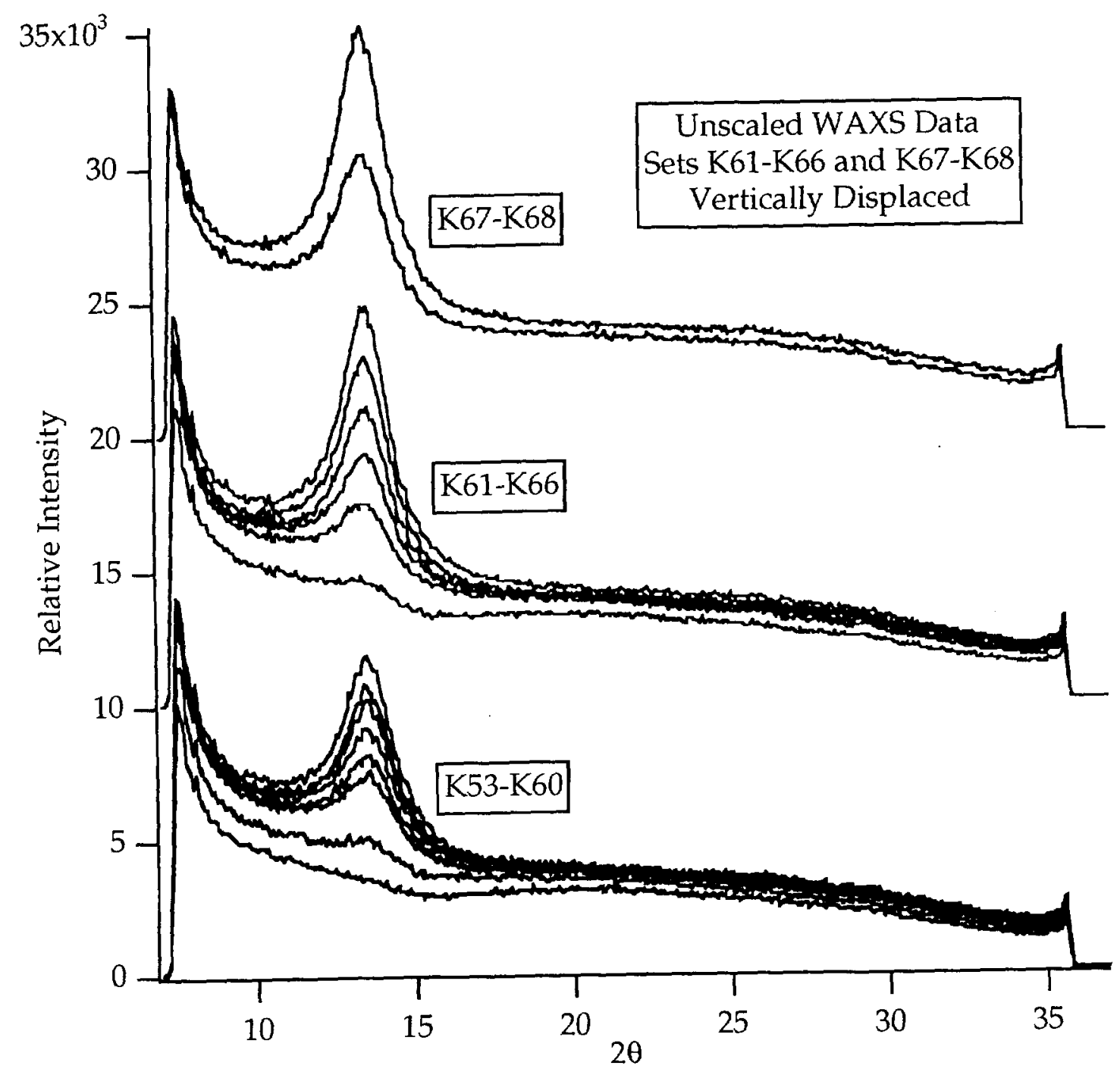

Figure 16. WAXS data for real time draw experiments. In contrast to previous WAXS plots, the data have not been scaled by the total number of counts. 
Appendix A. Table of Samples Run. All samples are Kel-F 800 unless otherwise specified. All samples that had been previously aged were held on ice until measured. All data collection times are $120 \mathrm{~s}$ unless otherwise specified

\section{Run Description and notes}

\section{8/11/99, starting about noon}

$\mathrm{K} 01$ lot 639 , shaving, aged at $60^{\circ} \mathrm{C}$ for $21 \mathrm{~d}$, run time $60 \mathrm{~s}$

$\mathrm{K} 02$ same as $\mathrm{K} 01$, collection time $120 \mathrm{~s}$

$\mathrm{K} 03$ the full $1 \mathrm{~mm}$ thickness piece that $\mathrm{K} 01$ was shaved from.

K04 data with no sample - a blank

$\mathrm{K} 05$ repeat of $\mathrm{K} 02$ with a different shaving

K06 dog bone sample of lot 720 stretched to $300 \%$ then aged $111 \mathrm{~h}$ at $40{ }^{\circ} \mathrm{C}$. The central part of the dog bone was cut out and measured. There was no apparent relaxation as it warmed up. This sample was oriented so that the draw direction was perpendicular to the 1-D detector.

$\mathrm{K} 07$ same sample as $\mathrm{K} 06$ but rotated so that the draw direction was parallel to 1-D detector

K08 same aging and material as K06, but not drawn. Full thickness ( $1 \mathrm{~mm}$ ) piece.

K09 a sliver off of sample used in K08, oriented horizontally

$\mathrm{K} 10$ same as $\mathrm{K} 09$ but rotated $90^{\circ}$

$\mathrm{K} 11$ dog bone sample of lot 720 stretched to $300 \%$ then aged $16 \mathrm{~h}$ at $55^{\circ} \mathrm{C}$. The central part of the dog bone was cut out and measured. There was no apparent relaxation as it warmed up. This sample was oriented so that the draw direction was perpendicular to the 1-D detector.

$\mathrm{K} 12$ same sample as $\mathrm{K} 11$ but rotated so that the draw direction was parallel to 1-D detector

K13 same aging and material as K11, but not drawn. Measured a cut sliver

K14 same as $\mathrm{K} 13$ rotated by $90^{\circ}$

K15 poly(chlorotrifluoroethane) (pCTFE) sample aged at $155^{\circ} \mathrm{C}$ for 17 days. measurement on full thickness ( $\sim 1 \mathrm{~mm}$ or a little less ?) sample.

K16 same as K15 but a thin slice to increase transmission

K17 pCTFE melted and rapidly quenched. Not aged at $\mathrm{T}$ - should be as amorphous as possible. Cut sliver measured.

K18 pCTFE aged at $155^{\circ} \mathrm{C}$ for 1 day. Thin cut sliver measured

K19 lot 639 shaving, unaged - amorphous

K20 Lot 7023.5 y old, sliver

$\mathrm{K} 21$ lot 639 aged at $40^{\circ} \mathrm{C}$ for $10 \mathrm{~d}$, sliver

$\mathrm{K} 22$ lot 639 aged at $40^{\circ} \mathrm{C}$ for $2.5 \mathrm{~d}$, sliver

$\mathrm{K} 23$ lot 639 aged at $60^{\circ} \mathrm{C}$ for $5.5 \mathrm{~h}$, sliver

$\mathrm{K} 24$ lot 639 aged at $70^{\circ} \mathrm{C}$ for $11.6 \mathrm{~d}$, sliver

8/12/99 starting about noon

$\mathrm{K} 25$ lot 639 aged $60^{\circ} \mathrm{C}$ for 21 days, sliver, $240 \mathrm{~s}$ data collection

K26 same as K25 but $1200 \mathrm{~s}$ data collection

K27 lot 639 unaged, fully amorphous, $240 \mathrm{~s}$ data collection

K28 same as K27 but 1200 s data collection 
K29 same sample as K06, dog bone sample of lot 720 stretched to $300 \%$ then aged $111 \mathrm{~h}$ at $40^{\circ} \mathrm{C}$, but about $24 \mathrm{~h}$ later. Sample was kept cool in mean time.

Sample draw direction is perpendicular to detector. $240 \mathrm{~s}$ data collection

K30 same as K 29 but 1200 s data collection

K31 same as K29 but parallel to detector, 240 s data collection

K32 same as K31, $1200 \mathrm{~s}$ data collection

K33 true blank - no sample $1200 \mathrm{~s}$

$8 / 12 / 99$ temperature studies starting in evening, $1 \mathrm{~mm}$ thick samples

K34 lot 639 amorphous, $25^{\circ} \mathrm{C}, 240 \mathrm{~s}$

$\mathrm{K} 35$ lot 639 amorphous, sample $\mathrm{K} 34,25^{\circ} \mathrm{C}, 120 \mathrm{~s}$

$\mathrm{K} 36$ lot 639 amorphous, sample $\mathrm{K} 35,40$ to $92^{\circ} \mathrm{C}$ over $120 \mathrm{~s}$

K37 lot 639 amorphous, sample K36, 120 to $172{ }^{\circ} \mathrm{C}$ over $120 \mathrm{~s}$

$\mathrm{K} 38$ lot 639 amorphous, sample $\mathrm{K} 37,200^{\circ} \mathrm{C}$

$\mathrm{K} 39$ lot 639 amorphous, sample $\mathrm{K} 38,200^{\circ} \mathrm{C}$

$\mathrm{K} 40$ lot 639 amorphous, sample $\mathrm{K} 39,200^{\circ} \mathrm{C}$

$\mathrm{K} 41$ lot 639 amorphous, sample $\mathrm{K} 40$, cooled to $30^{\circ} \mathrm{C}$ over about $1.5 \mathrm{~h}$. visual examination after data taken showed sample had melted and fused into the sample holder opening. There was some evidence of little bubbles.

$\mathrm{K} 42$ lot 639 amorphous, new sample, $\mathrm{T}=35$ to $82^{\circ} \mathrm{C}$ over $120 \mathrm{~s}$

$\mathrm{K} 43$ lot 639 amorphous, sample $\mathrm{K} 42,100^{\circ} \mathrm{C}$

$\mathrm{K} 44$ lot 639 amorphous, sample $\mathrm{K} 43,150^{\circ} \mathrm{C}$

$\mathrm{K} 45$ lot 639 amorphous, sample $\mathrm{K} 44,200^{\circ} \mathrm{C}$

$\mathrm{K} 46$ lot 639 amorphous, sample $\mathrm{K} 45,200^{\circ} \mathrm{C}$

$\mathrm{K} 47$ lot 639 amorphous, sample $\mathrm{K} 46,200^{\circ} \mathrm{C}$

$\mathrm{K} 48$ lot 639 amorphous, sample $\mathrm{K} 47,250^{\circ} \mathrm{C}, \%$ transmission varying significantly during data collection. May indicate flow or bubble formation

$\mathrm{K} 49$ lot 639 amorphous, sample $\mathrm{K} 48,300{ }^{\circ} \mathrm{C}, \%$ transmission continued to fluctuate widely during run.

$\mathrm{K} 50$ lot 639 amorphous, sample $\mathrm{K} 49,300^{\circ} \mathrm{C}$, data on screen looks like lost sample

K51 blank consisting of sample holder and two pieces of Kapton tap which were used in previous experiment to hold Kel-F 800 in place.

K52 blank consisting of empty sample holder and no Kapton tape

8/13/99 8:30 am. Real time draw experiments using amorphous lot 720 dog bones prepared by DeTeresa. Relatively thick samples, $240 \mathrm{~s}$ collection time. Draw direction in all cases perpendicular to detector. Draw Factor $(D F)=$ final stretched length divided by initial length. It appeared the draw was not uniform, but somewhat higher in the middle where the beam went through.

$\mathrm{K} 53$ undrawn, $\mathrm{DF}=1$, started with clamps $15 \mathrm{~mm}$ apart

$\mathrm{K} 54$ previous sample; $\mathrm{DF}=2.0$

$\mathrm{K} 55$ previous sample; $\mathrm{DF}=3.0$

K56 previous sample; $\mathrm{DF}=3.3$

$\mathrm{K} 57$ previous sample; $\mathrm{DF}=3.7$

K58 previous sample; $\mathrm{DF}=4.0$

$\mathrm{K} 59$ previous sample; $\mathrm{DF}=4.3$ 
K60 previous sample; $\mathrm{DF}=4.7$

K61 new sample, started with clamps $5 \mathrm{~mm}$ apart $-\mathrm{DF}=3.0$

K62 previous sample; $\mathrm{DF}=6.0$

K63 previous sample; $\mathrm{DF}=8.0$

K64 previous sample; $\mathrm{DF}=10.0$

K65 previous sample; $\mathrm{DF}=12.0$

K66 previous sample; $\mathrm{DF}=14.0$

K67 new sample, started with clamps $\sim 2 \mathrm{~mm}$ apart $-\mathrm{DF}=20$

K68 previous sample; $D F=35$; center of piece turned white - maybe induced crystallization?

This work was performed under the auspices of the U.S. Department of Energy by the University of California, Lawrence Livermore National Laboratory under Contract No. W-7405-Eng-48. 